ISSN: 0213-2052 - eISSN: 2530-4100

DOI: http://dx.doi.org/10.14201/shha201937185223

\title{
JULIA MAESA Y JULIA SOEMIAS EN LA CORTE DE HELIOGÁBALO: EL PODER FEMENINO DE LA DOMUS SEVERIANA
}

\section{Iulia Maesa and Iulia Soaemias at the Court of Elagabalus: The Female Power of the Severan Domus}

\author{
Pedro David CONESA NAVARRO \\ Universidad de Murcia. Università degli Studi di Roma, "Tor Vergata" \\ pedrodavid.conesa@um.es
}

Fecha de recepción: 27-8-2018; aceptación definitiva: 21-3-2019

ORCID: 0000-0003-2802-3178

RESUMEN: En este artículo pretendemos estudiar la relación que mantuvo el emperador Heliogábalo con su abuela Julia Maesa y su madre Julia Soemias. También abordaremos el papel que desarrollaron estas emperatrices dentro de la dinastía. La subida al poder de un emperador joven, Heliogábalo solo tenía 14 años cuando fue proclamado imperator por las tropas acantonadas cerca de Emesa, permitió que estas mujeres ejercieran un papel decisivo en la corte. Fueron capaces de establecer alianzas,

* Este trabajo ha sido posible gracias a la concesión de un Contrato Predoctoral FPI de la Fundación Séneca. Agencia Territorial de Ciencia y Tecnología de la Región de Murcia (19829/FPI/15). Miembro del Grupo de Investigación ARHIS (Arqueología Histórica y Patrimonio del Mediterráneo Occidental) (E041-08) de la Universidad de Murcia, cuyo investigador principal es el Dr. José Miguel Noguera Celdrán. Miembro del Grupo de Investigación Deméter. Maternidad, Género y Familia de la Universidad de Oviedo, cuya investigadora principal es la Dra. Rosa María Cid López. 
entrometiéndose en la esfera pública, e incluso, una de ellas, Julia Soemias, llegó a crear un Senado, todo esto según las fuentes clásicas. Sin embargo, ateniéndonos a los testimonios epigráficos y numismáticos parece que estas mujeres continuaron la tradición anterior, puesto que los títulos y honores recibidos fueron similares a los de sus predecesoras. Por ello, en este trabajo proyectamos crear un discurso coherente analizando las referencias de los autores clásicos a la luz de los testimonios numismáticos y epigráficos.

Palabras clave: Dinastía Severa; poder femenino; Julia Maesa; Julia Soemias; Heliogábalo.

ABSTRACT: In this paper we intend to study the relationship between Emperor Heliogabalus and his grandmother Julia Maesa and his mother Julia Soemias. We will also address the role played by these empresses within the dynasty. The rise to power of a young emperor, Elagabalus, who was only 14 years old when he was proclaimed imperator by the troops stationed near Emesa, allowed these women to play a decisive role in the court. They were able to establish alliances, to meddle in the public sphere, and even one of them, Julia Soemias, managed to create a Senate, all according to classical sources. However, according to epigraphic and numismatic testimonies it seems that these women continued the previous tradition, since the titles and honors received were similar to those of their predecessors. For this reason, in this paper we plan to create a coherent discourse analysing the references of classical authors in the light of numismatic and epigraphic testimonies.

Keywords: Severan Dynasty; female power; Iulia Maesa; Iulia Soeamias; Elagabalus.

\section{INTRODUCCIÓN}

La dinastía Severa fue instaurada a partir de un enfrentamiento bélico, llegando al poder Septimio Severo, primer emperador procedente de una provincia africana. La política de legitimación que desarrolló situó a las mujeres de su círculo más próximo en una posición visible, creando una atmósfera artificial donde la fortaleza familiar constituyó uno de los pilares fundamentales para la consolidación dinástica. Aunque habían pasado veinticinco años desde que Severo fue proclamado imperator de Roma y siete desde que Caracalla había sido asesinado ${ }^{1}$, la llegada de Heliogábalo

1. Septimio Severo fue proclamado emperador por las tropas acantonadas en Carnuntum el 9 de abril de 193 d. C., siendo ratificado posteriormente por el Senado y entrando en Roma en junio de ese mismo año. Cf. Kienast 2004, p. 156. La muerte de 
se vivió en un primer momento con gran alegría. Supuso el inicio del gobierno de un nuevo representante de la dinastía Severa, lo que se vio como una vuelta atrás a los años dorados de su fundador. Por tanto, pese a la distancia en el tiempo, el mensaje desplegado fue similar y el papel desarrollado por Julia Domna en los gobiernos de su marido y de su hijo, fue imitado por su hermana y sus sobrinas ${ }^{2}$. Las mulieres de la dinastía Severa tuvieron similares títulos y aparecieron en lugares insólitos como fueron los miliarios imperiales, privilegio del que sus predecesoras no gozaron ${ }^{3}$. Sin embargo, hay que precisar que las Augustae se mostraron en espacios públicos debido a que fue una manera más para extender el mensaje del emperador. Frente al varón que sí que ejerció imperium, el título de $A u$ gusta tuvo únicamente un carácter representativo y un valor honorífico ${ }^{4}$. Sin embargo, sí que se aprecian ciertas diferencias entre Julia Domna y sus sucesoras, como bien puntualizó Hidalgo de la Vega. Para empezar, pese a que también fue criticada por las fuentes clásicas ${ }^{5}$, la esposa de Septimio Severo contó con el apoyo de su marido y de Caracalla. Sin embargo, esta situación no se repitió con Julia Maesa y sus hijas. Los esfuerzos realizados por mantener la dinastía se basaron en pactos y uniones efímeras, vistas por sus contemporáneos como el resultado de maniobras políticas realizadas por mujeres interesadas e infames ${ }^{6}$. Ante la falta de un varón que

Caracalla se produjo el 8 de abril de 217 d. C. cerca de Carras. Cf. DC 78 (79), 4, 1; Hdn. 4, 13, 4-6; HA. Carac. 6, 6-7; 7, 1-3; HA. Macr.4, 7-8; MenÉnder Argǘn, 2003, p. 315; González Fernández y Sancho Gómez, 2006, p. 66; Sancho Gómez, 2011b, p. 78; Conesa Navarro, 2012; 2014 ed., p. 398; Hidalgo de la Vega, 2012, p. 153.

2. La importancia que las fuentes clásicas, así como la producción científica concedió a las mujeres de Heliogábalo, no se puede comparar con la prestada a Julia Domna, a su hermana y a las hijas de esta última. Concretamente, las esposas de Heliogábalo fueron: Julia Cornelia Paula (219-220; PIR ${ }^{2}$ I 660), Julia Aquila Severa (220-221, 221-22; PIR² I 648), Annia Aurelia Faustina (221, PIR $^{2}$ A 710), mientras que la mujer de Alejandro Severo fue Salustia Orbiana (226-227, PIR ${ }^{1}$ S 252). Sobre estas Augustae en concreto, cf. KIENAST, 2004, pp. $173-175$ y 179.

3. González Fernández, 2017, pp. 311-324.

4. CENERINI, 2009, p. 31.

5. Estas críticas parecen derivar de la descripción que se ofreció de la Augusta en la Historia Augusta. En ella se indica que Caracalla mantuvo relaciones sexuales con la esposa de Severo. Para ello, mencionó que realmente el hijo mayor del emperador nació de la unión de este con su primera esposa, Paccia Marciana. Cf. HA. Sev. 21,7; HA. Carac. 10, 1-4. Esto permitió que autores posteriores como Aurelio Víctor $(21,3)$ o Eutropio $(8,20,2)$ mencionaran esta noticia. Parece que Herodiano $(4,9,3)$ hizo referencia a dicha difamación cuando se le llama a Julia Domna con el apelativo de Yocasta. Sobre esta cuestión, fue estudiada con detalle por Penella, 1980, pp. 382-384. Más tarde, es mencionado por SAQUETE, 2018, p. 324 y nota 66 con las principales referencias clásicas.

6. Hidalgo de la Vega, 2012, pp. 159-160. 
defendiera los intereses de los jóvenes herederos, se creó una línea matrilineal que asumieron la hermana de la primera Augusta de los Severos, así como sus hijas, Julia Soemias y Julia Mamaea. Este hecho permitió que estas mujeres se inmiscuyeran en los asuntos más delicados del Imperio ${ }^{7}$. Si nos centramos únicamente en las noticias ofrecidas por las fuentes literarias, observamos que fueron cruciales en los asuntos de gobierno. Sin embargo, existe una descompensación entre estas y las aportadas por las referencias epigráficas y numismáticas ${ }^{8}$. Los honores que recibieron, señalados en diversas inscripciones y monedas, ya los encontramos en sus predecesoras.

Las fuentes literarias fueron críticas con Heliogábalo supuestamente por introducir ciertos cultos orientales en el corazón de Roma. Especialmente, se estableció el culto solar dentro del panteón romano en 220 d. C. ${ }^{9}$. No solo se adoró a una divinidad extranjera, sino que, incluso, antepuso este nuevo culto al del dios Júpiter, visto por Dion Casio como una auténtica ofensa ${ }^{10}$. Además, en la urbs se estuvieron desarrollando cultos lunares y semitas de carácter africano y oriental, a los que tendríamos que añadir aquellos de impronta indoeuropea procedentes de las esferas militares ${ }^{11}$. Por tanto, estamos de acuerdo con la afirmación de Cid López al decir que, los cuatro años del reinado de Heliogábalo (218-222) representaron uno de los periodos más orientales de todo el Imperio romano. La labor de Julia Maesa también la debemos encontrar en esta innovación religiosa y social. Solamente se distanció la hermana de Domna del hijo de Julia Soemias cuando observó el descontento creciente entre la sociedad ante las excentricidades que realizó el joven princeps ${ }^{12}$. Intentó persuadirle

7. SaAvedra Guerrero, 2000-2001, 42-43, pp. 856-857; GÜNTHer, 2016, p. 128.

8. Kettenhofen, 1979 , pp. 144-172.

9. D.C. 80 (80), 11, 1; Hdn. 5, 5, 8; HA. Elag. 3, 4; Kienast, 2004, p. 172. El templo fue construido en el Palatino, cerca del palacio imperial. En opinión de Birley, el pasaje de la Historia Augusta que mencionó la erección del templo al dios semita en Roma por parte de Heliogábalo fue realmente una alusión a Constantino. Cf. Birley, 1991, p. 44. Herodiano también indicó que se construyó otro templo a las afueras de Roma donde se transladó la figura del dios sobre un carro cubierto de oro y piedras preciosas. $C f$. Hdn. 5 , 6, 6-7. Por otro lado, la Historia Augusta mencionó que el emperador pensó en construir una gran columna por la que se subía a través de una escalera de caracol. En la parte superior de este monumento estaría coronada por la figura del dios El Gabal. Finalmente, no se construyó debido a que Heliogábalo quiso que fuera confeccionada de una piedra determinada procedente de Grecia. HA. Elag. 24, 7.

10. D. C. 80 (80), 11, 1; Potter, 2004, p. 156; Manders, 2012, p. 146; Scott, 2017, p. 11.

11. SANChO GÓMEZ, 2011a, p. 611.

12. Hdn. 5, 7, 1-2; CALDERINI, 1945, p. 13; Cid López, 1993, pp. 257-258. Sobre las actividades poco lícitas realizadas por Heliogábalo, cf. Lenfant, 2001, p. 53. 
para que modificara su forma de vestir, inapropiada para un varón romano ${ }^{13}$, así como la extravagancia religiosa que estuvo desarrollando. Sin embargo, finalmente optó por apoyar a su otro nieto, Alejandro Severo, para que fuera su sucesor ${ }^{14}$. En este trabajo nos ocuparemos por desarrollar no solo la relación mantenida entre Julia Maesa y Julia Soemias con Heliogábalo, sino también nos preguntaremos por el papel desempeñado por estas mujeres dentro de la corte imperial. Además de las narraciones transmitidas por los autores clásicos, también repasaremos los principales testimonios epigráficos y numismáticos con la intención de crear un discurso coherente.

\section{Julia Maesa, Julia Soaemia y Heliogábalo}

\subsection{Las referencias literarias}

Poco después de la muerte de Caracalla, en ese mismo mes de abril de 217 d. C., falleció Julia Domna en Antioquía ${ }^{15}$. Ante esta nueva situación, la hermana de la esposa de Septimio Severo y las hijas de esta se convirtieron en las únicas descendientes directas del último Antonino. Por aquel entonces, obligadas por Macrino, según informaron Herodiano y la Historia Augusta, regresaron a Emesa ${ }^{16}$. Tras fallecer su hermana, su sobrino y también su marido ${ }^{17}$, Julia Maesa fue consciente que se encontraba sin ningún apoyo. Lo normal habría sido que perdiera todo el prestigio alcanzado bajo el gobierno de Septimio Severo; sin embargo, Emesa resultó ser

13. Hdn. 5, 5, 3-6. Concretamente, cuando señaló el enfado de Maesa por la forma de vestir de su nieto, $c f$. Hdn. 5, 5, 5. Bravi señalaba que Heliogábalo estuvo reflejado en la Historia Augusta como uno de los principales emperadores que transgredieron los mores maiorum. Viene definido como pestis illa (HA. Elag. 10, 1). La impronta oriental se apreció en la indumentaria adoptada, en especial, en la introducción de gemas coloridas. Cf. BRAVI, 2007, pp. 80-82. Una crítica a la vestimenta del emperador también vino dada en Dion Casio. El senador bitinio dijo que empleó en público la túnica utilizada por los sacerdotes sirios. Cf. DC., 80 (80), 11, 2.

14. Hdn. 5, 7, 1-2.

15. Entre las propuestas estaría el suicidio tal y como apuntaron Herodiano o Dion Casio, aunque este último también señaló que pudo ser a consecuencia de un cáncer de pecho. Cf. D.C 78(79), 23, 6; Hdn. 4, 13, 8; GHedini, 1984, p. 15; Levick, 2007, p. 105; Conesa NaVArRo y González Fernández, 2016, p. 608.

16. Hdn. 5, 3, 2; HA. Macr. 9, 1; Kienast, 2004, p. 181; OKoń, 2013, p. 64. Casio informó que Maesa estuvo viviendo de nuevo en Emesa una vez que su hermana había fallecido. No señaló si fue a consecuencia de una decisión propia o si fue obligada por Macrino. Cf. D.C. 78 (79), 30, 3-4.

17. ICKS, 2013 , p. 56. 
un lugar idóneo para diseñar estrategias y conseguir apoyos que permitieran restablecer la dinastía. Además, hay que mencionar que, incluso antes de que Septimio Severo llegara a ser emperador de Roma, la hermana de Julia Domna gozó de una buena reputación e importantes contactos en su ciudad natal ${ }^{18}$. Por tanto, la maniobra de Macrino de apartar a Maesa de la capital imperial con el fin de disminuir su influencia fue un gran error. Precisamente, el regreso a la urbe siria fue lo que le permitió diseñar estrategias y alianzas que aceleraron la caída del antiguo prefecto del pretorio de Caracalla ${ }^{19}$ y que su nieto, Vario Avito Bassiano Antonino, conocido como Heliogábalo, fuera nombrado nuevo Augusto ${ }^{20}$.

Una de las primeras maniobras que emprendieron, al igual que anteriormente hizo lo propio Septimio Severo tras autoproclamarse hijo de Marco Aurelio y hermano de Cómodo ${ }^{21}$, fue legitimar su gobierno a través del parentesco. Extendió el rumor de que Heliogábalo era hijo de Caracalla y de Julia Soemias, lo que motivó a los soldados a que dejaran de apoyar a Macrino y se mostraran partidarios de la restauración dinástica ${ }^{22}$. Tal y como afirmó Morelli, estamos ante un clima de violencia de tal calibre que "salirono in succesione al potere, con false affermazioni di paternità e con improbabili adozioni ${ }^{23}$. Herodiano señaló que fue Julia Maesa la encargada de difundir la información entre los soldados, llegando a utilizar el soborno y sacrificando la reputación de su hija, pues fue esta última

18. Baharal, 1996, p. 52; Cordovana, 2018, p. 43. Herodiano mencionó que algunos soldados que iban a Emesa al santuario fueron clientes y protegidos de Julia Maesa. $C f$. Hdn. 5, 3, 9-10. De hecho, parece que Macrino respetó la posición de la Augusta, lo que permitió que Heliogábalo tuviera una vida acomodada. Cf. HA. Macr. 9, 5.

19. Cordovana, 2018, p. 43.

20. Hdn. 5, 5, 2.

21. Se hizo de manera efectiva en la primavera de 195 d. C. Cf. Kienast, 2004, p. 156; GonZÁlez FernándeZ y CONESA NAVARRO, 2017, p. 137. Beckmann pareció darle una mayor relevancia a Eutiquiano, pues dijo que realmente además de ser el instigador para que el ejército se revelara contra Macrino, llevó consigo al joven Avito al campamento para que fuera nombrado emperador sin el conocimiento de Julia Maesa y Julia Soemias. Palabras que extrajo de la obra de Dion Casio (78 (79), 31, 1-2). Además, mencionó que fue el encargado de extender el rumor de que Heliogábalo era hijo de Caracalla. En un principio puede que tanto la hermana de Domna como la madre de Avito no tuvieran ninguna ambición, sin embargo, debido a cómo se desarrollaron los acontecimientos, no tuvieron otra opción que apoyar la candidatura de Heliogábalo como nuevo emperador. Cf. BLECKManN, 2002, p. 282.

22. D. C. 78 (79), 32, 2-3; Hdn. 5, 3, 9-10; HA. Macr. 9, 4; HA. Elag. 2, 1-2; Eut. 8, 22; Frézouls, 1994, pp. 130-131; Lenfant, 2001, p. 52; BleCKMAnn, 2002, pp. 279-280; ANDO, 2012, p. 65; KeMEZIS, 2016, p. 350.

23. Morelli, 2010a, p. 471. 
en la Historia Augusta como meretrix ${ }^{24}$. En otro pasaje, por el contrario, comentó que dicho rumor fue extendido por la hermana de Domna y por sus propias hijas entre los soldados ${ }^{25}$.

Por otro lado, hay referencias de un tetradracma en la parte oriental del Imperio en el que supuestamente Heliogábalo está referenciado como hijo de Caracalla a través de la inserción de su efigie en el anverso, mientras que Plautilla está en el reverso ${ }^{26}$. Sin embargo, si el anterior rumor es difícil de sostener, esta hipótesis únicamente se sustentaría a partir de la acuñación comentada, a lo que habría que añadir los problemas que plantea su iconografía. No está del todo asegurado el emperador que está presentado; pues, además de Heliogábalo, también se especuló que dicha imagen puede ser la representación de Caracalla o Alejandro Severo. Esto nos permitiría afirmar que realmente Heliogábalo nació de la unión de Sexto Vario Marcello y de la hija mayor de Maesa ${ }^{27}$. A ello tenemos que sumarle que, como señaló Bleckmann, las primeras monedas que se acuñaron de Heliogábalo en 219 d. C. guardaron semejanzas con las de Caracalla ${ }^{28}$. Ayudado por la titulatura desarrollada en sus epígrafes, confirmaría que el parentesco del joven princeps y el hijo mayor de Septimio Severo se convirtió en una estrategia de suma importancia para conseguir la aprobación del ejército.

Tras un acuerdo entre Maesa, el tutor de Avito, Gannys y P. Valerio Comazon (Eutiquiano) ${ }^{29}$, se presentaron la hermana de Domna junto con

24. Hdn. 5, 3, 9-11 y 5, 4, 1; HA. Macr. 7, 6, HA. Elag. 2, 1; de Arrizabalaga y Prado, 2014, p. 33. En la vita de Caracalla, se indicó que, tras ejercer el imperium durante seis años, el sucesor de Septimio Severo dejó un hijo llamado Marco Antonino Heliogábalo. Cf. HA. Carac. 9, 1-2. Sin embargo, siguiendo a Rowan, 2012, pp. 164-165: "The effort put into publicising the claim no doubt reflects the fact that the genealogy was false. Elagabalus was given Caracalla's name (Marcus Aurelius Antoninus) and his portraits were consciously crafted to recall the deceased emperor".

25. Hdn. 5, 7, 3. Concretamente, menciona que las tres Augustae pregonaban el adulterio de Caracalla para que, tanto Heliogábalo como Alejandro Severo, fueran aceptados por el ejército.

26. BMC V, p. cliv. Mattingly por su parte remite a la obra de BelLINGER, 1940, pp. $54 \mathrm{ff}$.

27. Raepsaet-Charlier, 1983, pp. 186-187; Raepsaet-Charlier, 1999, p. 215; Kienast, 2004, p. 172; VARNER, 2004, p. 188; OKOŃ, 2013, p. 77.

28. Bleckmann, 2002, p. 280.

29. Dion Casio en dos fragmentos señaló los colaboradores que supuestamente tuvo Julia Maesa que ayudaron a que su nieto Heliogábalo fuera proclamado emperador. El primero de ellos, ya comentado, D. C. 78 (79), 31,1, describió a Eutiquiano como una persona que había agradado a la plebe con juegos gimnásticos y diversiones. Más adelante, Casio $(79(80), 39,4)$ habló de un tal Comazon que, pese a que no había sido formado para tener ningún tipo de responsabilidad, llegó a ser cónsul y prefecto de la ciudad. Su cognomen derivaba de los mimos y bufones. Ambas personas guardan ciertas semejanzas al 
PEDRO DAVID CONESA NAVARRO

JULIA MAESA Y JULIA SOEMIAS EN LA CORTE DE HELIOGÁBALO:

EL PODER FEMENINO DE LA DOMUS SEVERIAN

el resto de su familia por la noche en el campamento de la legio III Gallica, acantonada en Raphanae, cerca de Emesa, donde, finalmente, Avito fue reconocido "nuevo Antonino" el 18 de mayo de 218 d. C. ${ }^{30}$. Si seguimos el relato ofrecido por Herodiano, dicha legión estuvo constituida por un amplio número de soldados partidarios de Julia Maesa. Esto permitió que no fuera del todo difícil adentrarse en el campamento militar ${ }^{31}$. Unido a los apoyos que tuvo en el ejército, se sumó el hecho de que hizo su entrada junto con los sucesores "legítimos" del hijo mayor de Septimio Severo. Habría que esperar un mes más, al 8 de junio, para que finalmente Macrino fuera derrotado y al año siguiente para que Heliogábalo llegara a Roma ${ }^{32}$.

Herodiano fue directo al mencionar que las motivaciones para querer restaurar la dinastía estuvieron en los deseos de Maesa de no vivir como una particular o desterrada ${ }^{33}$. Heliogábalo, a instancias de su madre, recibió una educación oriental. Los cultos procedentes de siria, especialmente los relacionados con el culto solar, se fueron asentando con arraigo en

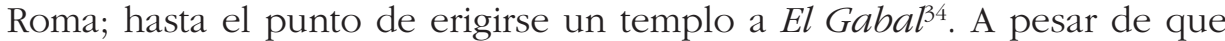
Mamaea, madre de Alejandro Severo, terminó por distanciarse de la tradición oriental con el fin de evitar el trágico desenlace de su sobrino y hermana, tanto Heliogábalo como Alejandro Severo fueron educados con los mismos preceptos y, siguiendo con la tradición familiar, fueron nombrados sacerdotes del dios solar ${ }^{35}$. Precisamente los cultos que se impusieron bajo

estar vinculados con los espectáculos y danzas. Tal у como indicó OкоŃ, es difícil suponer que dos individuos de tan similares características se dieran en un mismo espacio de tiempo. Además, si nos centramos en el análisis epigráfico, observamos que solo Comazon apareció en algunas inscripciones. Por tanto, estamos de acuerdo con esta historiadora al decir que, todas aquellas teorías que se postularon en que Genny y Eutiquiano podrían ser la misma persona, carecen de justificación. Sobre esta cuestión con bibliografía. Cf. OкоŃ, 2013, p. 77 nota 6. Comazon comenzó su carrera en el reinado de Cómodo como soldado en Tracia. Después, pasó a ser comandante de la legio III Gallica en 218 d. C. y ya bajo el gobierno de Heliogábalo alcanzó los puestos más relevantes llegando a ser prefecto del pretorio. Cf. Mennen, 2011, p. 168. Este pasaje también vino señalado en Cordovana, 2018, p. 44 .

30. Hdn. 5, 3, 11-12; Baharal, 1996, p. 52; VARner, 2004, p. 188; Rowan, 2012, p. 164; ОкоŃ, 2013, pp. 77-78.

31. Hdn. 5, 3, 9-10,12. Calderini mencionó que los soldados fueron partidarios de Caracalla. Cf. CALDERINI, 1945, p. 11.

32. Kemezis, 2016, p. 351. Eutropio señaló que, pese a que en principio fue recibido con gran expectación tanto por el Senado como por el ejército, pronto se corrompió con toda clase de vicios. Cf. Eut. 8, 22.

33. Hdn. 5, 3, 11.

34. Sobre esta cuestión. Cf. Di Palma, 1999, pp. 333-336; Sancho Gómez, 2011a, pp. 595-623.

35. Hdn. 5, 3, 3-4; SaAvedra Guerrero, 2000-2001, p. 857. 
su gobierno, ayudado por la "excesiva" presencia de estas mujeres en la esfera pública, fueron aspectos determinantes para que fueran criticados tanto el princeps como su madre por sus contemporáneos.

A ello tendríamos que sumarle las importantes cantidades de dinero entregadas al ejército, constituyéndose a partir del siglo III d. C. en un factor determinante para conseguir la estabilidad. Es por ello por lo que, una de las primeras medidas emprendidas por Maesa fue precisamente alentar a los soldados a que se unieran a su causa mediante la promesa de importantes sumas de capital. Se pretendió asegurar la fides del sector militar, manifestado entre otras cosas, a partir de las acuñaciones monetales de Heliogábalo con las leyendas fides militum ${ }^{36}$ y fides exercitus ${ }^{37}$. Sobre esta cuestión Kosmetatou llegó a plantear que una de las causas del derrocamiento de Alejandro Severo y de su madre se debió precisamente a la insistencia de Julia Mamaea de no sobornar al ordo equester ${ }^{38}$.

En apenas un año y dos meses desde la muerte de Caracalla, subió al solio imperial un adolescente de catorce años con extrañas actitudes. Su abuela junto con su madre Soemias y una serie de personalidades relacionados con el ejército, fueron los encargados de dirigir las riendas imperiales en un primer momento ${ }^{39}$. Los problemas urgentes que había que despachar en la parte oriental fueron solventados por Maesa y sus consejeros, ya que el nuevo princeps carecía de experiencia y formación ${ }^{40}$. Pocos días más tarde, entre el 13 y 14 de ese mes de junio de 218 d. C., Heliogábalo fue nombrado Pater Patriae y Pontifex Maximus y ampliada dicha titulatura a partir del año 220 d. C. a Sacerdos Amplissimus de Invicti Solis Elagabal, Pontifex Maximus ${ }^{41}$. Tras pasar su primer invierno como

36. RIC IV, Elag. 72e; 72 f, 73b, 73d, 74, 75, 76b, 76d, 77 y 78 .

37. RIC IV, Elag. 66, 67e, 67f, 68b, 68d, 69b, 69d, 70e, 70f, 71b.

38. Kosmetatou, 2002, p. 414: "In order for an emperor to be certain of his power to hope to retain some order in the empire, large bribes were needed to ensure the loyalty of the tropos. It is posible, through difficult to prove in the current state of the evidence, that Mamaea may have tried top ut an end to this practice, hence her reputation as a miser, wich reportedly cost her and her son's lives".

39. Siguiendo a Kemezis (2014, p. 83), el gobierno de Heliogábalo fue el primero de una serie de períodos liderados por emperadores jóvenes en los que, realmente, el poder fue por detentado un grupo heterogéneo de senadores y personalidades relacionadas con el ordo equester.

40. Hdn. 5, 5, 1. Sobre la ayuda que recibió Heliogábalo al principio de su gobierno, también lo mencionó Dion Casio, aunque el mal estado de conservación del papiro condiciona a que algunos datos no se tomen por seguros. Al parecer, estuvieron asesorados por unos pocos libertos, personalidades del rango ecuestre y senadores de la ciudad de Emesa. Cf. D.C. 78 (79), 33, 2-3.

41. Sobre los títulos, así como sus cronologías, Cf. KIENAST, 2004, p. 172. 
nuevo purpurado en Bitinia, marchó a Alejandría y tras eliminar a algunos partidarios del anterior emperador, Avito llegó a Roma en el año 219 d. C. Su entrada en la urbs estuvo acompañada de un importante cortejo sirio, e inmediatamente después, comenzó a realizar ritos religiosos dedicados a dioses extranjeros. Dichas prácticas fueron la primera toma de contacto con la sociedad romana y el inicio del distanciamiento del emperador con sus habitantes ${ }^{42}$. Se hizo llamar sacerdos de El Gabal, pues para él este título tuvo más relevancia que el de imperator ${ }^{43}$. Además, todos los cognomina ex virtute, a excepción de aquellos de carácter religioso, como el de Pius Felix, terminó rechazándolos ${ }^{44}$.

Por primera vez en Roma se dio una situación sin precedentes. A los cultos extranjeros que parecieron relegar a los tradicionales, se sumó una estirpe de mujeres sirias con una fuerte carga sacerdotal ${ }^{45}$. El carácter absorbente de la anciana hermana de Domna, hizo que los datos referentes a Soemias fueran escasos en comparación con la esposa de Septimio Severo, su madre o hermana, lo que permitiría pensar que su influencia fue relativa. Sin embargo, esta apreciación puede ser matizada. En la Historia Augusta fue retratada la hija mayor de Maesa como una de las principales influencias que tuvo Heliogábalo en su gobierno, siendo partícipe no solo de su muerte, sino también de su mala gestión ${ }^{46}$. Una de las primeras medidas que emprendió la poderosa abuela del emperador fue enterrar las cenizas de Julia Domna en el mausoleo de Adriano junto con las de Geta $^{47}$. En el año 218 d. C., no pudiéndose establecer una fecha segura, Julia Maesa ${ }^{48}$ fue distinguida ya con el título de Augusta, sucediendo lo mismo con su hija Soemias ${ }^{49}$. Uno de los aspectos más destacados de estas mujeres fue que estuvieron presentes en diferentes sesiones del Senado. En una ocasión, Heliogábalo entró a la cámara acompañado de su abuela, consciente de que Maesa tuvo más autoridad que él y, por lo tanto, fue imprescindible para llevar a cabo sus propósitos ${ }^{50}$. En otro momento, Dion

42. Hdn. 5, 5, 7-8; González Fernández y Sancho Gómez, 2006, p. 67.

43. D.C. 79 (80), 11, 1.

44. Hidalgo de la Vega, 2012, p. 154.

45. Tanto Julia Domna como Julia Maesa fueron hijas de Julio Basiano, sumo sacerdote del templo de El Gagal de Emesa. Entre otros, Cid López, 1993, p. 256; Hidalgo DE LA VEGA, 2012, p. 135.

46. WALLinger, 1990, p. 98.

47. D.C. 78 (79), 24, 3; Levick, 2007, p. 145; Hidalgo de la Vega, 2012, p. 153.

48. Kienast, 2004, p. 181.

49. Kienast, 2004, p. 175.

50. HA. Elag. 12, 3. Otra ocasión donde también vemos a Maesa en el Senado. $C f$. HA. Elag. 15, 6-7. 
Casio informó que cuando se sancionó la adopción de Alejandro Severo además de concederle el título de César, Julia Maesa y Julia Soemias estuvieron presentes en el Senado ${ }^{51}$. Sin embargo, el hecho de que permanecieran junto a Heliogábalo y Alejandro Severo puede que respondiera a la oficialidad que se le pretendió dar al acto. De hecho, en la Historia Augusta, a instancia de los propios senadores, durante la primera sesión celebrada bajo el gobierno de Heliogábalo, fue convocada la madre del emperador a la que se la definió como clarissima, título reservado a los patres conscripti. Además, su presencia no fue meramente nominal, ya que ocupó un lugar destacado junto a los cónsules y actuó como testigo ${ }^{52}$. Estos factores insólitos permitieron que, una vez asesinada Julia Soemias junto con su hijo, se prohibiera la entrada de otra mujer en la cámara ${ }^{53}$. Tanto Babelon ${ }^{54}$ como Benario ${ }^{55}$ mencionaron que la participación de Julia Maesa en este órgano fue el principal argumento para que se le otorgara el título de mater senatus. Tesis que puede ser discutida, ya que, por esa misma razón, Domna, que también gozó del mismo honor, habría participado en el Senado y no tenemos constancia de ello. Por tanto, pensamos que esta concesión respondió realmente a una estrategia con la que se pretendió equiparar a Maesa con su hermana. Por otro lado, Chastagnol planteó

51. D.C. 80 (80), 17, 2. Herodiano informó que la adopción de Alejandro Severo se dio porque Julia Maesa observaba que el emperador estaba perdiendo apoyos. Temerosa de verse privada de los privilegios alcanzados buscó una estratagema para que finalmente su nieto mayor accediera y adoptara a su primo, dándole en un primer momento el título de César, además de compartir el consulado. Sin embargo, este historiador no mencionó la presencia de las Augustae en el momento en el que se sancionó la adopción. $C f$. Hdn. 5, 7, 1-4. De igual forma, en la Historia Augusta se señaló en tres ocasiones que Alejandro Severo recibió el título de César después del fallecimiento de Macrino. Sin embargo, parece mencionar que fue a propuesta del Senado y en ningún momento se alude a la presencia de las Agustae, ni tampoco que fuera adoptado por su primo. Cf. HA. Elag. 5, 1-2; 10, 1; Alex. 1, 2-3; Chastagnol, 1974, p. 4; Conesa Navarro, 2018, p. 251.

52. HA. Elag. 4, 1-3; Chastagnol, 1979, p. 3.

53. HA. Elag., 18, 3.

54. Babelon, 1957, p. 221.

55. Para argumentar dicha hipótesis, además de apoyarse en las narraciones de la Historia Augusta, el autor se fundamentó en una inscripción encontrada en Puteoli que plantea diversos problemas por su estado fragmentado y la restitución realizada ( $A E, 1956$, 144). Argumentó que la asociación de esta inscripción con Julia Domna no puede ser sostenida debido a la alusión de la diosa Caelestis, que encajaría más fácilmente si la conectamos con Julia Soemias. El único aspecto que quedaría por solucionar sería la alusión de senatus en la inscripción que él entendió como una prueba que confirma la vinculación de la emperatriz con el Senado. Cf. Benario, 1959, pp. 10-13. Sin embargo, dicha hipótesis fue rebatida por Gilliam llegando a decir: "but Benario's arguments and conclusions seem entirely unacceptable». Cf. Gilliam, 1963, p. 26. Este debate lo desarrollaremos con profundidad más adelante. 
que nos encontramos frente a una exageración de los autores clásicos. Si tenemos en cuenta que las noticias de la entrada de estas Augustae al Senado procedieron de Herodiano y la Historia Augusta, tendríamos que relativizar la información; y, por supuesto, no podemos hablar de mujeres con similares prerrogativas a las de los senadores ${ }^{56}$. Por tanto, su inclusión en la cámara pudo tener un carácter meramente representativo ya que ellas, y concretamente la hermana de Domna, encarnó la continuidad dinástica materializada en los jóvenes Heliogábalo y Alejandro Severo que fueron los descendientes legítimos de Caracalla. Aspecto que entroncaría con la información transmitida por Dion Casio, quien las presentó en un momento puntual y señalado como fue la elección de un sucesor imperial.

Por su parte, Soemias dio un paso más al instituir, supuestamente, un mulierum senatus en la colina del Quirinal, donde también esuvo presente Julia Maesa ${ }^{57}$. Los asuntos que se discutieron tuvieron reconocimiento legal a través de senatus consulta. Sin embargo, el autor de la Historia Augusta los definió como ridicula, además de frívolos, pues se dirimieron únicamente cuestiones femeninas ${ }^{58}$. Se ha tratado bastante sobre esta institución, dudándose incluso de su existencia. Especialistas como Hidalgo de la Vega ${ }^{59}$ y más reciente Cockell ${ }^{60}$, sintetizaron las principales posturas desarrolladas $^{61}$. Es posible, tal y como propuso Molinier Arbo, que este pasaje respondiera a una invención de la Historia Augusta ${ }^{62}$. Parecidos argumentos fueron esgrimidos con anterioridad por Straub o Wallinger y, más reciente, por Saquete, quienes rechazaron la existencia del senado

56. Chastagnol, 1979, p. 5: "Aucune autre femme n'a bénéficié d'un tel honneur, et la façon dont en parle l'Histoire Auguste, même si elle presente la chose avec quelque exagération, suffit à démontrer qu'il s'agit là d'une exception qui a paru aux contemporains et à la postérité tout à fait insolite; encore ni Soaemias ni Maesa n'ont -elles été, en l'occurrence, de réels membres du Sénat".

57. HA. Elag. 4, 3; Cid López, 1993, p. 256; Frézouls, 1994, p. 131; VArner, 2001, p. 48; Hidalgo de la Vega, 2012, p. 154; Molinier Arbo, 2016, p. 59; Saquete, 2018, p. 325

58. HA. Elag. 4, 3-4; Chastagnol, 1979, p. 24; Cid López, 1993, p. 256; Straub, 2001, p. 233. Los temas tratados fueron: la vestimenta que podían utilizar las mujeres, estableciéndose una clasificación en función del rango social. También se dispuso que aquellas que pertenecieran a un status social acomodado, pudieran emplear carruajes, ya fueran guiados por animales de tiro o por caballos. Otros asuntos fueron el uso de literas confeccionadas con hueso o cuero, además de otros muchos detalles.

59. Hidalgo de la Vega, 2012, p. 155.

60. COCKell, 2015, p. 34.

61. Para conocer los principales títulos que han trabajado este senado femenino, $c f$. Molinier ARBo, 2016, pp. 59-60 nota 45.

62. Molinier ARBO, 2016, pp. 60-61: "Ce burlesque principat feminin et féministe illustre d'abord la grande fantaisie de l'écrivain". 
femenino ${ }^{63}$. Por el contrario, Hidalgo de la Vega opinó que la manera en la que fueron definidas las decisiones que se llevaron a cabo, de ridicula, denotaría una auténtica actividad de reglamentación y, por lo tanto, terminó aceptando su existencia ${ }^{64}$.

Salvo en el caso de Lanuvio donde se ha encontrado una inscripción que habla de una curia mulierum, en el resto de las ciudades del Imperio no se tiene constancia de un cuerpo cívico de similares características ${ }^{65}$. Su naturaleza es difícil de precisar, aunque tendría carácter religioso ${ }^{66}$. Sin embargo, dejando al margen los problemas derivados de la Historia Augusta, de instituirse realmente un "senaculum" femenino habría sido ampliamente censurado por los escritos grecolatinos, lo que resulta extraño que salvo en la vita de Heliogábalo en el resto de las fuentes literarias no viniera señalado. Por tanto, teniendo en cuentas estas premisas, podemos poner en tela de juicio que realmente se diera un senado compuesto por mujeres. Nadie duda en que las Augustae relacionadas con Heliogábalo desarrollaron un papel importante en su gobierno ${ }^{67}$. Wallinger planteó que esta noticia no tuvo ningún transformado histórico ${ }^{68}$. Sin embargo, la negación del mismo no implica, a nuestro parecer, que no se basara en un hecho contrastable. La decisión de permitir a las mujeres entrar al Senado ya supuso una fractura de los mores maiorum. Sabemos por Tácito que Agripina, madre de Nerón, también ejerció una fuerte autoridad sobre su hijo. En una ocasión el Senado celebró una de sus sesiones en el Palacio y, aunque ella no estuvo presente directamente, sí que pudo escuchar a los patres conscripti detrás de una cortina ${ }^{69}$. Este hecho insólito ni tan siquiera se podría comparar con lo ocurrido durante la dinastía Severa. Siguió narrando el historiador clásico que, en otro momento, una delegación de armenios se presentó ante el emperador para dirimir algunas cuestiones. La Augusta estuvo dispuesta a presidir junto con su hijo la reunión; sin embargo, Séneca aconsejó a Nerón a que fuera al encuentro de su madre y que no la dejara estar presente para evitar un escándalo ${ }^{70}$. Agripina se mantuvo siempre a la sombra, aunque fuera detrás de una cortina; sin embargo, Julia Maesa y Julia Soemias presidieron las sesiones junto con los emperadores. Por

63. Straub, 1966, pp. 221-240; Wallinger, 1990, p. 99-100; Saquete, 2018, p. 325.

64. Hidalgo de la Vega, 2012, p. 155.

65. Pasqualini, 2005, p. 262. Sobre la inscripción en concreto, cf. CIL XIV, 2120.

66. Pasqualini, 2005, p. 269.

67. StRAub, 1966, p. 221.

68. WALLINGER, 1990, p. 100.

69. Tac. Ann. 13, 5, 1-2.

70. Tac. Ann. 13, 5, 2. Concretamente, este último aspecto viene expresado por el autor de la siguiente manera: "Ita specie pietatis obviam itum dedocori". 
tanto, puede ser entendido este senaculum femenino como una crítica no solo hacia Heliogábalo, sino también a los patres conscripti, estos últimos por permitir a mujeres poder asistir a sus sesiones.

El descontento fue en aumento, mostrando un rechazo cada vez mayor hacia el joven emperador. Finalmente, el 11 de marzo de 222 d. C. fueron asesinados a manos de los pretorianos tanto Heliogábalo como Julia Soemias ${ }^{71}$. La caída del princeps trajo consigo también la de su madre, además de la posterior damnatio memoriae a la que fueron sometidos ${ }^{72}$. Tras matarlos, mutilarlos y arrastrarlos por toda la ciudad, finalmente los cuerpos del emperador y de Julia Soemias fueron arrojados a las cloacas que iban a parar al río Tíber ${ }^{73}$. Lo interesante, es que según la Historia Augusta la muerte de la Augusta estuvo justificada, pues había llevado una vida depravada, repleta de vicios al igual que su hijo ${ }^{74}$.

Uno de los principales problemas derivados de la época Severiana son las fuentes literarias. Solo Dion Casio sabemos con seguridad que fue coetáneo $^{75}$. Tradicionalmente, Herodiano también se ha enmarcado dentro de la dinastía de los Severos; aunque recientes estudios se posicionaron por situarlo en un período posterior ${ }^{76}$. Estos dos autores presentan cierta similitud en sus obras, lo que permitió hipotetizar que los cinco primeros libros de Herodiano estuvieron influenciados por la obra del senador bitinio $^{77}$. Sin embargo, Bowersock señaló que se observa cierta independencia

71. Eut. 8, 22; González Fernández y Sancho Gómez, 2006, p. 67; Varner, 2001, p. 48.

72. Sobre esta cuestión, cf. VARNER, 2004, pp. 188-195.

73. Hdn. 5, 8, 8-9. Parecida descripción fue la ofrecida en D.C. 80 (80), 20, 2. El senador bitinio indicó que el cuerpo de Heliogábalo fue a parar al río, no pronunciándose en lo que le ocurrió al cuerpo sin vida de Soemias. Al inicio del libro ochenta, Casio entre los adjetivos que empleó para definir a Heliogábalo habla de Tißepivós, en alusión a que fue arrojado por el río. Cf. D.C. 80 (80), 1, 1. La Historia Augusta matizó que, tras ser apresado el emperador que se encontraba escondido en una letrina, finalmente fue asesinado (HA. Elag. 16, 4-5). Se intentó lanzar su cuerpo a una cloaca, pero finalmente se optó por arrojarlo al río desde el puente Milvio (HA. Elag. 17, 1-4).

74. HA. Elag. 18, 2-3; SAQueTE, 2018, p. 325. Llamativa fue la afirmación realizada por Calderini (1945, p. 14) sobre la muerte de Maesa que, entre otras cosas, indicó: "e così Soemia, natura sensuale e leggiera, pagava, travolta nel destino del figlio, la sua incoscienza con la morte più atroce".

75. Concretamente, redactó su obra durante la primera mitad del siglo III d. C. Muchos de los datos aportados fueron fruto de sus propias vivencias como senador en la corte de la dinastía de los Severos. Cf. ScotT, 2017, p. 1.

76. Entre las últimas propuestas destacaríamos la formulada por Sidebottom. Este autor lo situó en torno al año 260 d. C. Sin embargo, dicha teoría fue cuestionada por Polley, que fecha el trabajo de Herodiano entre la década del 240 o 250 d. C. Cf. Sidebottom, 1997; POlley, 2003.

77. Scheithauer, 1990, p. 335; SCOtT, 2018, pp. 437-438. 
con respecto a lo narrado por Casio y la Historia Augusta, además de no no guardar semejanzas ni tan siquiera esta última obra con los anteriores autores $^{78}$. Por tanto, si seguimos este planteamiento, podríamos pensar que las tres obras fueron independientes, algo que tampoco es del todo cierto. Diferentes pasajes contenidos en la obra de Casio y Herodiano guardan semejanzas, lo que nos permitiría asegurar que el segundo autor conoció perfectamente la obra del primero. La complejidad que entraña la Historia Augusta ha centrado la atención de numerosos especialistas, materializándose dichas reflexiones no solo en diferentes libros o trabajos especializados, sino también en coloquios y debates ${ }^{79}$. Tal y como señaló recientemente Velaza, los problemas derivados permiten que no haya un consenso entre los estudiosos y las diferencias que presenta la obra nunca lleguen a solucionarse ${ }^{80}$. Las vitae de Heliogábalo y Alejandro Severo muestran a dos imperatores jóvenes, pero con caracteres antagónicos. El primero representa lo negativo, alejado de los mores maiorum ${ }^{81}$; mientras que, Alejandro Severo, aunque en ocasiones es criticado por una excesiva dependencia hacia su madre ${ }^{82}$, respondió al ideal del buen soberano ${ }^{83}$. Si a ello le sumamos que las biografías que se desarrollan a partir de la mitad del siglo III d. C. en adelante carecen de valor histórico o por lo menos los datos que se presentan tiene que ser tomados con suma precaución ${ }^{84}$, condiciona a que la investigación resulte más compleja. Esto permite que, tal y como hemos podido comprobar, Julia Soemias fue ampliamente criticada por esta obra frente a Herodiano y Casio que apenas la mencionaron; y, cuando lo hicieron, siempre fue descrita a la sombra de su madre. Sin

78. BOWERSOCK, 1975, p. 236.

79. El primer coloquio se produjo en el año 1962 y a partir de 1990 sería organizado por diferentes universidades, siendo la de Bonn la primera sede universitaria que reunió a especialistas. El último realizado ha sido en el Düseldorf, publicados los resultados apenas unos años. Cf. SANCHO Gómez, 2018, pp. 9-10. Sobre la publicación del último coloquio, $c f$. BLECKMANN Y BRANDT, 2017.

80. VelazA, 2017, pp. 701-702.

81. Esta visión negativa se observa en diferentes estudios. Por ejemplo, Cordovana (2018, p. 44) describió el gobierno de Heliogábalo de la siguiente manera: "Il regno di Elagabalo è dipinto nelle fonti come caratterizzatto da ogni genere di eccessi, turputidine e lascivie, tanto che viene considerato come uno dei peggiori imperatori che si possano annoverare nella storia imperiale di Roma".

82. Hdn. 6, 8, 3; Eutr. 8, 23; Baugman 2017, p. 113; Conesa Navarro, 2018, pp. 250-252.

83. Ruggini, 1991, p. 125, FréZouls, 1994, p. 128.

84. Kemezis, 2018, p. 307. Esta oposición de caracteres incluso se vió en las madres de los emperadores por parte de la historiografía. Por ejemplo, Calderini $(1945$, p. 10) retrató así a las hijas de Maesa en uno de sus trabajos: "Soemia, molle e voluttuosa, soprattutto ai piaceri, Mamaea timida e inclinata al misticismo, desiderando invence un migliore avvenire per il giovane figlio". 
PEDRO DAVID CONESA NAVARRO

JULIA MAESA Y JULIA SOEMIAS EN LA CORTE DE HELIOGÁBALO:

EL PODER FEMENINO DE LA DOMUS SEVERIAN

duda, la acusación de meretrix junto con la institución de un senado femenino, fueron los aspectos más reprochables por el pensamiento romano. Por tanto, estas mujeres fueron utilizadas por las fuentes clásicas para criticar no solo a ellas, sino al emperador e, incluso, a los varones próximos a la dinastía.

\section{LOS VESTIGIOS EPIGRÁFICOS}

Si tenemos en cuenta las referencias literarias que hablaron de Julia Domna y las comparamos con las de Maesa, Soemias o Mamaea, podríamos pensar que estas últimas gozaron de una mayor importancia que se traduciría en una variada panoplia de títulos, superiores a los de la esposa de Septimio Severo. Sin embargo, esta última marcó unos preceptos que fueron imitados por sus sucesoras; especialmente por su hermana y su sobrina Julia Mamea, ya que la madre de Heliogábalo no gozó de tantos honores como las otras dos ${ }^{85}$. Benario señaló que para el caso de Soemias los datos epigráficos no fueron inferiores a los de su tía Domna o a los de su hermana Mamaea ${ }^{86}$. Sin embargo, esa apreciación no es del todo cierta, ya que con el transcurso del tiempo se han encontrado diversas inscripciones de Julia Domna que exceden en cantidad al resto de Augustae de la dinastía. Además, Julia Soemias no tuvo la misma consideración que su madre en el gobierno de Heliogábalo, eso sin contar que, una vez fallecida la hermana de Julia Domna en agosto de 224 d. C. ${ }^{87}$, Julia Mamaea fue la encargada de guiar a su hijo Alejandro Severo. Kettenhofen, por su parte, expuso que los testimonios sobre Julia Maesa, que no superan la veintena, son escasos y difíciles de interpretar, no pudiéndose precisar ni tan siquiera el momento en el que se le concedió el rango de Augusta $^{88}$. Lo mismo podríamos decir de su hija, Julia Soemias, de la que, incluso, el número de inscripciones es menor que el de su madre y hermana. Su estudio resulta mucho más complejo no solo por la damnatio memoriae a

85. NADOLNy, 2016, p. 123. Sobre esta cuestión Kettenhofen ya señaló que los honores recibidos por Julia Maesa prácticamente estaban vinculados con los de su hermana. $C f$. KeTtenHOFEN, 1979, p. 144.

86. Benario, 1959, p. 10.

87. Kienast, 2004, p. 181.

88. KetTenhofen, 1979, pp. 144 y 151. Un dato interesante lo constituyen las inscripciones en griego. De los pocos ejemplos conservados, observamos dos en concreto encontradas en Frigia dedicadas a Julia Maesa y que se datan en el gobierno de Alejandro

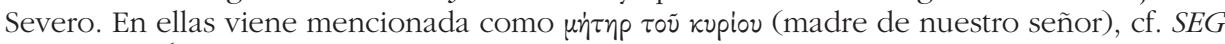
XXXIII, 1136 y 1137. 
la que fue sometida tras su muerte en marzo de 222 d. C., sino, también, por el escaso tiempo en el que estuvo en la corte imperial. De momento, a falta de nuevos hallazgos, solo sabemos con seguridad que fue investida Augusta y mater Augusti ${ }^{89}$. En la epigrafía griega, además de $\sum_{\varepsilon} \beta \alpha \tau \dot{\eta}$, también se muestra con parecidas locuciones a las latinas como fueron: $\mu \eta \eta \eta \eta p$

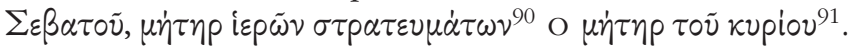

En el reciente estudio de Nadolny se analizaron 307 inscripciones escritas en latín relacionadas con las emperatrices de la dinastía de los Severos en función de los dedicantes de dichos epígrafes. En una primera categoría estarían englobadas aquellas promocionadas por personalidades del sector militar y por funcionarios imperiales. Un segundo apartado lo componen los epígrafes erigidos por distintas ciudades o por funcionarios municipales, mientras que, por último, estarían los financiados por privados. De todas las categorías, habría que destacar las promocionadas por el sector militar, lo que demuestra la situación compleja que se vivió durante la dinastía Severiana. Tras Julia Domna, le seguía Julia Mamaea, que junto con la esposa de Septimio Severo representan el $75 \%$ del total. En su mayoría las inscripciones estuvieron localizadas en las tres provincias africanas (Consularis, Numidia y Mauretania Caesariensis) ${ }^{92}$. Si nos centramos en los casos particulares de Julia Maesa y Soemias, vemos también que la proporción de inscripciones dedicadas por el ejército fue superior al resto de categorías. Concretamente, cinco para el caso de Julia Maesa, cuando en los otros dos apartados contaron con dos epígrafes respectivamente. Por el contrario, su hija tiene dos ejemplares en los dos primeros apartados y ninguno en el tercero ${ }^{93}$.

Maesa, aunque con interrogantes, parece que el 30 de mayo de 218 d. C. ${ }^{94}$ fue investida Augusta, mostrándose en las inscripciones como Iulia Maesa Augusta, Avia Augusti ${ }^{95}$. Una inscripción singular dedicada a Heliogábalo y encontrada en Roma, aparecen Julia Maesa y Soemias con el

89. Kienast, 2004, p. 175: Окоń, 2018, p. 145.

90. SEG XL, 349.

91. SEG LIV, 1777.

92. NADOLNY, 2016, p. 129.

93. NADOLNY, 2016, p. 129 y especialmente la tabla que adjunta en dicha página.

94. Kienast, 2004, p. 175. Kettenhofen basándose en datos epigráficos, estableció como terminus ad quem la fecha del 14 de julio de 218 d. C., cf. KetTenhofen, 1979, p. 145 .

95. Africa Proconsularis: AE 1912, 28; ILAfr 334. Numidia: AE 1912, 155; CIL VIII, 2715 (p 1739); CIL VIII, $2564=$ CIL VIII, $18052=D 470=C B I 782=A E$ 1947, $201=A E$ 1978, 889. Etruria: AE: 1993, 668; Raetia: AE 2004, 1062. Dacia: CERom-27/28, 01301. Roma: CIL VI, 2104 (p 864, 3261, 3824) = CIL VI, $32388=$ CIL I, $2(\mathrm{p} \mathrm{717,} \mathrm{739,} \mathrm{831)} \mathrm{=} \mathrm{CLE}$ $1=D 5039(\mathrm{p} 184)=C F A 100=\operatorname{ILLRP} 4=\operatorname{CSE} \mathrm{p} 211=A E 1976,12=A E 2003,4 ; C I L \mathrm{VI}$, 
apelativo de domina sua, refiriéndose al emperador, mientras que, con el caso de la segunda, además de resaltar que fue la madre de Heliogábalo también señala que fue domina nostra ${ }^{96}$. Independientemente de los títulos conferidos al princeps, en los que se insistió en su gran fortaleza, además de considerarse emperador de todos, encontramos aspectos llamativos en esta inscripción. Para empezar, como se ha indicado, la inclusión de la palabra domina fue algo inusual. Sin embargo, hay que advertir que en esa parte concreta del epígrafe se encuentra fragmentada, conservándose únicamente las tres últimas letras de la primera palabra (nae). Esto permite que no podamos asegurar la presencia de este vocablo en la inscripción, pese a que la reconstrucción sea la más lógica. Además, observarnos que viene referenciada en primer lugar Julia Maesa y no la madre de este último. Este hecho atestiguado en otros ejemplos relacionados con Heliogábalo, así como con Alejandro Severo, demostraría la supremacía de la hermana de Domna con respecto a sus hijas ${ }^{97}$. Lo normal habría sido que estuvieran colocadas en un orden inverso. Sin embargo, como nos recuerdan las referencias literarias, fue Julia Maesa quien apostó por restablecer la dinastía a través de alianzas. Además de domina, otros adjetivos fuera de lo común y relacionados con Julia Maesa fueron los de sanctissi$m a^{98}$ o carissima $a^{99}$. Por tanto, la superioridad de Maesa con respecto a sus hijas no solo se apreció en la posición de su nombre en las inscripciones, sino también, tal y como indicó Nadolny, en los honores conferidos que sobrepasaron los de carácter oficial. Estos los encontramos en inscripciones promocionadas por privados, que vendrían a expresar su fidelidad y

$\overline{40679=}$ AE 1954, $28=$ AE 1956, 202; CIL VI, 40679a = CIL VI, 1079. Apulia et Calabria: CIL IX, 790. Latium et Campania: CIL X, $6002=$ D 476. Dacia: ILFPotaissa $14=$ AE 2012, 1210.

96. CIL VI, 40679a = CIL VI, 1079: [Imp(eratori) Caesari M(arco) Aulrelio Antonino Invicto Pio Felici Augusto / [indulgentissimo] ac super omnes principes fortissimo / [et Maesae Aug(ustae) domilnae suae et Iuliae Aug(ustae) matri eius dominae nostr(ae) /; NADOLNY, 2016, p. 121.

97. AE 1954, 28; CIL VIII, 2564; CIL VIII, 2715; KetTenhofen, 1979, p. 144. Esta situación se repitió también en el gobierno de Alejandro Severo. El orden normal era que Julia Mamaea, madre del emperador, apareciera antes que el nombre de Maesa de la siguiente forma: Iulia Mamaeae Aug(ustae) filio Iuliae Maesae Aug(ustae). Cf. AE 1981, 902; CIL VIII, $26547=$ ILAfr $528=$ LBIRNA 484. KOSMETATOU, 2002, pp. 399-400. Sin embargo, también nos encontramos ejemplos en orden invertido. Cf. CIL VI, $36775=D 484$ (p 171). Lo mismo podríamos decir de la epigrafía griega. Concretamente, un miliario hallado en la Cirenaica, además de mostrarse Maesa antes que su hija Soemias, en la línea 4 se indica que Heliogábalo es hijo de Caracalla. Cf. SEG LIV, 1777.

98. $A E$ 2000, 409; CIL VI, 36775=D 484, p. 171 (esta inscripción hace alusión al gobierno de Alejandro Severo, por lo que Julia Maesa aparece junto con su hija Julia Mamaea); CIL XI, 3774. Sobre esta cuestión, $c f$. KetTenhofen, 1979, p. 145; Nadolny, 2016, p. 123.

99. SpuIt- 18-R, 10= AE 2000, 409. 
lealtad hacia la casa reinante ${ }^{100}$. Salvo estas excepciones, el resto de las condecoraciones otorgadas fueron las habituales. Se piensa que los títulos de mater castrorum ${ }^{101}$ et mater senatus no fueron dados de manera oficial, produciéndose en mayo de 218 d. C., paralelamente a la concesión de Augusta ${ }^{102}$. Lo mismo podríamos decir del título mater castrorum et exercitum, atestiguado en un miliario en la antigua ciudad de Thamugadi, en Numidia, datado entre 225 d. C. y 226 d. C. ${ }^{103}$

Sabemos que, junto con el título de Augusta, el de mater castrorum fue el más representado en las inscripciones de Julia Domna. Dos terceras partes aparece la esposa de Septimio Severo condecorada con dicho honor, un $90 \%$ del total de sus inscripciones ${ }^{104}$. Por tanto, asumiendo que en gran medida los honores de Julia Maesa fueron similares a los de su hermana, es lógico pensar que también la alusión a "madre de los campamentos" la encontraríamos tanto en sus epígrafes como en los de sus hijas. Mientras que hallamos referencias de dicho título en la epigrafía de Julia Maesa a través de las alusiones de mater castrorum et senatus ${ }^{105}$ y mater castrorum et exercitum ${ }^{106}$, así como en Julia Mamaea, tanto en latín como en griego ${ }^{107}$, no parece ocurrir lo mismo con la madre de Heliogábalo. Kienast propuso que lo obtuvo en mayo de 218 d. C. junto al resto de condecoraciones $^{108}$. Esta hipótesis se sustentaría a partir de una referencia

100. NAdOlNy, 2016, p. 124.

101. Inscripciones bajo el gobierno de Heliogábalo: 1) CIL VIII, $2564=$ CIL VIII, 18052 $=D 470=C B I 782=A E$ 1947, $201=A E$ 1978, 889. Este epígrafe se data bajo el gobierno de Alejandro Severo. 2) CIL VIII, $2564=C I L$ VIII, $18052=D 470=C B I 782=A E$ 1947, 201 $=A E$ 1978, 889; $A E$ 1981, 902 .

102. Sobre esta cuestión, ha sido señalado entre otros por Kettenhofen, 1979, p. 146; LichtenBERgER, 2011, p. 360. Concretamente, Kienast (2004, p. 181) dijo lo siguiente: «30 Mai (¿) 218. Mit dem Augustatitel geehrt: Iulia Maesa Augusta, Avia Augusti (die Titel mater castrorum und mater senatus sind nicht offiziell)".

103. $A E 1981,902$.

104. LichtenBERGER, 2011, p. 360.

105. CIL VIII, $2564=C I L$ VIII, $18052=D 470=C B I 782=A E 1947,201=A E 1978$, 889.

106. $A E$ 1981, $902=$ AntAfr $-1980-172,21$.

107. En latín, algunos ejemplos son: CIL XI, 1175 = MantVel p 117; AE 1999, 1828; CIL VIII, 15512 = CIL VIII, $26554=$ ILTun 1385; CIL VIII, $26457=$ ILTun $1385=$ Dougga 1 , $\mathrm{p}$ $125=A E$ 2005, 1686; Posters p $131=$ LBIRNA $518=C R A I-2002-328=A E 2002,1681=A E$ 2007, 1718; CIL VIII, 1 (p 2287) = CIL VIII, $10990=$ IRT $908=$ LBIRNA 517; CIL VIII, 15386 $=$ CIL VIII, $26126=$ LBIRNA 525; CIL VIII, $10767=$ CIL VIII, $16849=I L A l g-1,1097=L B I R N A$ $521=A E$ 2013, 110; CIL III, $7955=$ IDR-3-2, 262; ILD 269 = CERom-2, $138=$ CERom-4, 281 $=$ CERom $-18,784=$ ZPE-120-259 = AE 1983, $834=A E$ 1998, 1092; SEG XXVIII, 577.

108. Sobre esta cuestión KIENAST, 2004, p. 175. Este autor menciona que la titulatura de la Augusta sería la siguiente: Iulia Soaemias (Bassiana) Augusta, mater Augusti, mater 
de Herodiano. Este autor, cuando relató el deceso de Heliogábalo y su madre, dijo que eliminaron a Julia Soemias pese a estar allí en calidad de Augusta y madre, ya que la vergüenza que sintieron los militares hacia el princeps fue superior ${ }^{109}$. Sin embargo, no contamos con ningún testimonio epigráfico ni numismático que confirme dicha afirmación. A ello tenemos que sumarle la ambigüedad del texto propuesto, pues no dejó del todo claro Herodiano si esa maternidad estuvo relacionada con el emperador o con las tropas. Por tanto, nos adherimos a la opinión de Kettenhofen ${ }^{110}$, que se mostró reticente a pensar que Julia Soemias fuera nombrada mater castrorum. Sorprende que solo sea a partir del testimonio del autor clásico la única mención al respecto. Teniendo en cuenta lo ampliamente representado en Julia Domna, así como su presencia en inscripciones relacionadas con Julia Maesa y Julia Mamaea, permite desechar la hipótesis de que la madre de Heliogábalo fuera nombrada "madre de los campamentos". Por tanto, sostenemos que únicamente fue condecorada como Augusta, que lo recibió el 16 de mayo de 218 d. C. ${ }^{111}$. En las inscripciones viene señalada como Iulia Soaemias Augusta ${ }^{112}$ o Iulia Soaemias Bassiana Augustae ${ }^{113}$. Sobre esta última forma, hay una inscripción procedente de Latium et Campania que está dedicada a Sexto Vario Marcello y que fue promocionada por su esposa. La alusión a su condición de Augusta es sustituida por el rango de clarissima femina, máxima distinción que pudo tener una mujer perteneciente a los ordines superiores de la escala social ${ }^{114}$. También en el soporte epigráfico hay que mencionar que, junto al título de Augusta, está señalada su parentela con el emperador (Mater Augisti nostri).

Otra inscripción interesante sería la estudiada por de Franciscis en 1954, procedente de Puteoli1 ${ }^{115}$. Se encontró en un estado bastante fragmentario y con importantes lagunas. Con algunas variaciones a la

\footnotetext{
castrorum.

109. Hdn. 5, 8, 8 .

110. KetTenhofen, 1979 , pp. 152-155.

111. KienAST, 2004, p. 175; GÜNTHER, 2016, p. 120.

112. Roma: $C I L$ VI, $40679=A E$ 1954, $28=A E$ 1956, 202. Dacia: ILFPotaissa $14=A E$ 2012, 1210. Numidia: LBIRNA $481=$ AE 1928, 36.

113. Mauritania Tingitana: $I A M-S, 851=A E$ 1987, 1130.

114. CIL X, $6569=I G-14,911=D 478=$ Chiron $-1982-226=A E$ 2014, 1455: Sex(to) Vario Marcello / proc(uratori) aquar(um) c(entenario) proc(uratori) prov(inciae) Brit(anniae) CC proc(uratori) rationis / privat(ae) CCC vice praeff(ectis) pr(aetorio) et urbi functo / c(larissimo) v(iro) praef(ecto) aerari(i) militaris leg(ato) leg(ionis) III Aug(ustae) / praesidi provinc(iae) Numidiae / Iulia Soaemias Bassiana c(larissima) f(emina) cum fili $(i)$ $s /$ marito et patri amantissimo.
}

115. Sobre la publicación original. Cf. Benario, 1959, p. 11 nota 13. 
interpretación original, Merlin volvió a publicarla apenas dos años más tarde ${ }^{116}$. El contexto arqueológico en el que se encontró tampoco ayudó a solucionar los problemas derivados del epígrafe, pues su emplazamiento original debió de ser el templo al que se alude y el contexto en el que se encontró la inscripción fue totalmente diferente. El epigrafista que ofreció su lectura planteó que se aludía a Julia Domna. Sin embargo, apenas tres años más tarde, Benario propuso que la persona mencionada no era la mujer de Septimio Severo, sino la madre de Heliogábalo, Julia Soemias ${ }^{117}$. Entre otras cuestiones, Benario pensó que de ser Julia Domna, no tendría sentido que la alusión et patriae estuviera ausente en el texto. De igual forma, se alude a la presencia de la diosa Venus Caelestis, divinidad estrechamente relacionada con Julia Soemias, especialmente a partir de los testimonios numismáticos, mientras que no encontramos una correlación similar con Julia Domna. De igual forma, planteó que la fórmula tota domus diuina fue una expresión dada entre los 217 a 218 d. C. ${ }^{118}$.

Pese a la argumentación proporcionada por Benario, apenas unos años más tarde, fue duramente criticada por Gilliam, quien retomó la idea primigenia ${ }^{119}$. Para ello, propuso que el texto, debido a su mal estado de conservación y a las lagunas que presenta, es imposible afirmar de manera categórica cualquier tipo de hipótesis que exceda de las letras conservadas. Aun aceptando que fuera Julia Soemias, no tendría sentido insistir en la alusión a su condición de mater senatus cuando esa parte precisamente ha sido una reinterpretación y no parte del contenido conservado. Además, el nombre de la emperatriz aparece como Iulia Augusta y esta forma solo se desarrolló en los epígrafes que mencionaron a la esposa de Septimio Severo. De igual forma, la alusión a la diosa Venus Caelestis se sustenta a partir de una letra que además de una "c", también podría ser una "g" o una "q", por lo que, pese a que fue un buen planteamiento, no dejó de ser eso, una mera especulación ${ }^{120}$. Todos estos argumentamos expresados por Gilliam, permitieron que no fuera aceptada la teoría expuesta por Benario. Por tanto, los honores de mater senatus et patriae que se podían vincular a Julia Soemias no suelen ser tenidos en cuenta. De hecho, por ejemplo, Kienast únicamente menciona que Soemias fue honrada como mater Augusti

116. $A E 1956,144$.

117. Benario, 1959, pp. 9-14.

118. BENARIO, 1959, pp. 10-13

119. Gilliam, 1963, pp. 26-29.

120. Gilliam, 1963, pp. 26-27. 
y mater castrorum $^{121}$, aunque, tal y como hemos podido comprobar, este último título también presenta problemas.

\section{LAS ACUÑACIONES MONETALES}

Caracalla y Plautilla al no tener descendencia ${ }^{122}$, permitió que la hermana de Domna, Julia Maesa, fuera el único lazo de unión entre Septimio Severo y Heliogábalo. La legitimación por vía masculina a través de la agnatio fue sustituida por un linaje femenino a través de la cognatio. Esto podría explicar que, frente a las mujeres de Heliogábalo, que presentaron escasos testimonios numismáticos, se tomara la decisión de intensificar los tipos individualizaron con Julia Maesa y Julia Soemias ${ }^{123}$. En el caso de la primera se ensalzaron virtudes relacionadas con la fecundidad, expresadas en alegorías como la Pudicitia, Pietas Augusta y Fecunditas Augusta. En este mismo sentido se dieron también las monedas de Julia Soemias ${ }^{124}$. En líneas generales, las titulaturas que recibieron ambas estuvieron relacionadas con su faceta maternal, aspecto que se puede extrapolar a los testimonios epigráficos. Esta uniformidad, repetida por todas las mujeres imperiales, no se distanció en gran medida de las alegorías desarrolladas por sus predecesoras $^{125}$, siendo Venus la más recurrida. De hecho, las emperatrices a lo largo de toda la Historia de Roma compartieron una serie de valores como fueron la prosperidad, fecundidad o la continuidad que se desarrollaron en diferentes soportes como los retratos, estatuas o monedas. Esto se debió a que se constituyeron en verdaderos exempla para el resto de las mujeres del Imperio ${ }^{126}$. Sin embargo, también hay que mencionar que cada Augusta empleó algunos elementos distintivos que las individualizaba. Por lo tanto, las monedas constituyen un testimonio importante no solo para conocer la ideología del momento, sino también para obtener una imagen

121. Kienast, 2004, p. 175.

122. La aparición de una moneda de Plautilla sosteniendo un niño en brazos y con la leyenda Pietas augg. junto con un testimonio epigráfico relacionado con los ludi saeculares del 204 d. C. sirvieron para pensar que Plautilla y Caracalla tuvieron descendencia. Cf. Gagé, 1934, pp. 63-67. Sin embargo, dicha teoría ha sido descartada. Cf. González Fernández y Conesa Navarro, 2014, p. 37; Conesa Navarro y González Fernández, 2016b, pp. $153-155$.

123. GÜNTHER, 2016, p. 127.

124. SAAVEDRA GuerRero, 2006, p. 725.

125. Benario, 1959, pp. 9-14; Kettenhofen, 1979, pp. 75-113; Kosmetatou, 2002, pp. 398-414; ROWAN, 2012, p. 173.

126. Domínguez Arranz, 2009, pp. 218-219. 
más fiel de cómo fueron en realidad las representadas a través de las características fisionómicas y peinados que presentan.

Por ejemplo, según Günther, entre los aspectos más notables que existieron entre las emperatrices Severas habría que destacar que Julia Domna, en su mayoría, se limitó a reproducir los prototipos desarrollados por Faustina la Menor $^{127}$. Si bien es cierto, durante la dinastía de los Severos se produjo un incremento considerable en las emisiones con virtudes que fueron continuadas por sus sucesores. Solo se superaron estas acuñaciones bajo el gobierno de Maximino. En este caso, virtudes femeninas como la Pudicitia se desarrollaron con especial ahínco en las monedas de Julia Domna ${ }^{128}$, lo que no nos sorprendería que fuera precisamente esta alegoría la más atestiguada en los ejemplos relacionados con Julia Maesa. Por su parte, Plautilla continuó con los utilizados por su suegra, aunque también se produjeron algunas variaciones, mientras que Maesa destacó por emplear alusiones militares, algo que también terminaría reproduciendo Orbiana $^{129}$. En contraposición al Catálogo del Museo Británico que diferenció claramente dos cecas que acuñaron monedas -la de Roma y la de la zona oriental-, en el RIC no se produce dicha distinción, pues señaló que todas aquellas vinculadas a la domus de Heliogábalo, Julia Paula, Aquila Severa, Soemias y Mamaea, son difíciles de precisar los tipos producidos en Siria de los de Roma a excepción de unos escasos ejemplos, por lo que resulta casi imposible realizar una sistematización ${ }^{130}$. Otra diferencia marcada en este caso por Morelli es que, en las emisiones de Julia Maesa, Soemias y Mamaea de carácter provincial o aquellas extraordinarias, se observa claramente las facetas maternales ${ }^{131}$.

Comenzando a analizar a las emperatrices por separado, en primer lugar, nos encontramos con la poderosa abuela Julia Maesa. Pese a que, en los testimonios epigráficos, los títulos y honores que recibió no distaron de aquellos que ostentó Julia Domna, parece que en las monedas sí que se dieron ciertas variaciones. Por ejemplo, a diferencia de lo que ocurrió con la esposa de Septimio Severo, en los ejemplos tanto de Julia Maesa como en los de Julia Soemias aparecen únicamente como Augustae, sin añadirle otro título honorífico ${ }^{132}$. Su nombre está referido de las siguientes formas: Iulia Maesa Aug. o de manera desarrollada: Iulia Maesa Augusta.

127. GÜNTHER, 2016, p. 157.

128. MuÑoz Muñoz y MarTínez López, 2014, p. 140.

129. GÜNTHER, 2016, p. 157.

130. RIC IV ${ }^{2}$, p. 27

131. Morelui, 2006, p. 75.

132. Nadolny, 2016, p. 121. 
A diferencia de Domna pocos han sido los ejemplos en los que apareció la emperatriz junto con el emperador. Solo se ha documentado un denario en el que en el anverso muestra el busto drapeado de Heliogábalo y girado hacia la derecha y en el reverso la imagen de Julia Maesa proyectada hacia la misma dirección ${ }^{133}$.

Siguiendo el planteamiento de Rowan que, aunque analizó únicamente las monedas producidas en plata, nos puede ayudar a entender a través de sus porcentajes cuáles fueron las virtudes más desarrolladas en las monedas de Maesa. En primer lugar, con un $46 \%$ del total, estaría la Pudicitia $^{134}$ (fig. 1), contando con un total de 990 ejemplares $^{135}$. En segundo lugar, tendríamos que hablar de la alegoría a Saeculi Felicitas ${ }^{136}$ (fig. 2), representada por 570 testimonios $^{137}$. Este último ya fue desarrollado por sus predecesoras, especialmente por Julia Domna ${ }^{138}$. El mensaje que se quiso transmitir supuso el de continuidad dinástica y la felicidad que fue que gobernaran de nuevo en Roma emperadores dignos de su cargo como fueron los Severos. Aquí también podríamos incluir el grupo de monedas con la leyenda Felicitas Publica ${ }^{139}$ o Temporum Fel(icitas $)^{140}$ cuyo mensaje fue similar. En tercer lugar, estaría la Pietas que muestra a la divinidad en los reversos en actitud de sacrificio, delante de un altar y sosteniendo una caja de incienso ${ }^{141}$. El tema de la Fecunditas ${ }^{142}$ también fue recurrente en

133. RIC IV ${ }^{2}$, p. 45 n. ${ }^{\circ}$ 208; BMC V, p. 539 n. ${ }^{*}$. La leyenda del anverso era: Imp. Antoninus Pius Aug. Mientras que en el reverso: Iulia Maesa Aug.

134. Pudicitia: Anv: Iulia Maesa Aug.: RIC IV ${ }^{2}$, p. 50 n. ${ }^{\circ}$ 267-269; BMC V, p. 541 n. 76-78. Pudicitia S.C.: Anv: Iulia Maesa Aug.: BMC V, p. 599 n. ${ }^{\circ} 395$, p. 601 n. ${ }^{\circ} 404-405$. Pudicitia S.C.: Anv: Iulia Maesa Augusta: RIC IV², 61 n. ${ }^{\circ} 417-420$; BMC V, p. 599 n. ${ }^{\circ} 391-$ 394.

135. ROWAN, 2011, pp. 265-266 fig. 14; Ib., 2012, p. 217 fig. 72.

136. Saeculi Felicitas: Anv.: Iulia Maesa Aug.: RIC IV ${ }^{2}$, p. 50 n. ${ }^{\circ} 270-273$; BMC V, p. 541 n. ${ }^{\circ}$ 79-83. Saeculi Felicitas S. C.: Anv.: Iulia Maesa Aug.: RIC IV ${ }^{2}$, p. 61 n. ${ }^{\circ} 421-424$; $B M C$ V, p. 599, n. ${ }^{\circ} 396$; p. 600 n. ${ }^{\circ}$ 397-401; p. 601 n. ${ }^{\circ}$ 406-407. También contamos con ejemplos acuñados en la parte oriental. Saeculi Felicitas: Anv.: Iulia Maesa Aug.: BMC V, p. 578 n. ${ }^{\circ} 300-301$.

137. ROWAN, 2011, p. 216.

138. RIC $\mathrm{IV}^{1}$, p. 111 n. ${ }^{\circ} 159$; p. 114 , n. $^{\circ} 175$; p. 115 n. ${ }^{\circ} 181 \mathrm{a}-181 \mathrm{c}$.

139. Felicitas Publica: Anv.: Iulia Maesa Aug.: RIC IV ${ }^{2}$, p. 49 n. ${ }^{\circ} 251$. Un denario híbrido con el reverso de Julia Mamaea también se ha atestiguado con esta leyenda: Felicitas Publica: BMC V, p. 542 n. ${ }^{\circ}$ b.

140. Temporum Fel.: Anv.: Iulia Maesa Aug.: RIC IV ${ }^{2}$, p. 50 n. ${ }^{\circ} 274 ; B M C$ V, p. 578 n. ${ }^{*}$.

141. Rowan, 2011, p. 216.

142. Fecunditas Aug.: Anv: Iulia Maesa Aug.: RIC IV ${ }^{2}$, p. 49 n. ${ }^{\circ} 249 ; B M C$ V, p. 539 n. ${ }^{\circ}$ 61-65 (estante). Fecunditas Aug.: RIC IV ${ }^{2}$, p. 49 n. ${ }^{\circ}$ 250; BMC V, p. 540 n. ${ }^{\circ}{ }^{*}$. Fecunditas: Fecunditas Augustae S.C.: Anv: Iulia Maesa Aug.: BMC V, p. 600 n. ${ }^{\circ} 403$; Anv: Iulia Maesa Augusta: RIC IV ${ }^{2}$, p. 61 n. ${ }^{\circ} 410-411$. 
las emisiones de Julia Maesa, lo mismo que ocurrió con sus hijas. Desde el momento en el que Heliogábalo concedió el rango de Augusta tanto a su madre como a su abuela, en las monedas emitidas para estas emperatrices comenzaron a ensalzarse el tema de la fecundidad y de la maternidad, algo que no se alejó de los cánones típicos femeninos. Sin embargo, adquirió una mayor dimensión debido al clima de violencia en el que se sucedieron los acontecimientos en relación con su llegada al poder. Aquí encontramos una vez más el papel protagonista de estas emperatrices, ya que ellas fueron las que portaron y permitieron el avance dinástico.

La leyenda Fecunditas la encontramos en diversas variantes, tanto estante como sedente, portando una cornucopia y un niño que parece tenderle la mano ${ }^{143}$. Sobre esta última en particular, su datación ha sido problemática y de igual forma, impreciso ha sido su significado. Morelli explicó las dos teorías que se plantearon para identificar al personaje infantil. O bien podría ser la personificación de Heliogábalo, que fue proclamado princeps gracias a la estrategia realizada por su abuela tras decir que fue hijo legítimo de Caracalla, o también puede que representase al propio Alejandro Severo, debido a su nombramiento como César en el año $221 \mathrm{~d}$. C. ${ }^{144}$. En otra gran proporción son las monedas en las que aparece en los anversos la representación de la diosa Juno, que suele aparecer sosteniendo una pátera y cetro ${ }^{145}$. A diferencia de otras acuñaciones, en el caso de Juno se ha podido definir claramente una producción de cuño oriental ${ }^{146}$, mientras que la mayor parte fueron producidas en Roma ${ }^{147}$. Otra virtud ampliamente representada en las monedas de Maesa fue la Pietas $^{148}$, que

143. MorelLi, 2010b, p. 145.

144. Morelli, 2010b, pp. 145-146.

145. ROWAN, 2011, p. 265.

146. Iuno: Anv: Iulia Maesa Aug.: RIC IV $\mathrm{IV}^{2}$, p. 49 n. ${ }^{\circ} 255$.

147. Iuno: Anv: Iulia Maesa Aug.: RIC IV ${ }^{2}$, p. 49 n. ${ }^{\circ}$ 253-254; BMC V, p. 540, n. ${ }^{\circ} 66-68$. Iuno S.C.: Anv: Iulia Maesa Augusta: RIC IV ${ }^{2}$, p. 61 n. ${ }^{\circ} 412-413$; BMC V, p. 598 n. ${ }^{\circ}$ †. Iuno S. C.: Anv: Iulia Maesa Aug.: BMC V, p. 600 n. ${ }^{\circ}$ †. Iuno Conservatrix: Anv: Iulia Maesa Aug.: RIC IV ${ }^{2}$, p. 49 n. ${ }^{\circ}$ 257; BMC V, p. 577 n. 297 (con pavo real); Iuno Conservatrix: Anv: Iulia Maesa Aug.: RIC IV ${ }^{2}$, p. 49 n. ${ }^{\circ} 258$ (sin pavo real). Iuno Regina: Anv: Iulia Maesa Aug.: RIC IV ${ }^{2}$, p. 50 n. ${ }^{\circ}$ 259. Iuno Regi: Iulia Maesa Aug.: RIC IV ${ }^{2}$, p. 50 n. ${ }^{\circ} 259$.

148. Pietas Aug.: Anv.: Iulia Maesa Aug. RIC IV ${ }^{2}$, p. 50 n. ${ }^{\circ}$ 263-266; BMC V, p. 540 n. ${ }^{\circ}$ 70-72, p. 541 n. ${ }^{\circ} 73-74$. Pietas Augusti: Anv: Iulia Maesa Aug. BMC V, p. 541 n. ${ }^{\circ} 75$. Pietas Augusta S.C.: Anv.: Iulia Maesa Augusta: RIC IV IV $^{2}$ p. 61 n. ${ }^{\circ} 414-415$; BMC V, p. 598 n. ${ }^{\circ}$ 389; p. 599 n. ${ }^{\circ}$ 399. Pietas Augusta S.C.: Anv.: Iulia Maesa Aug.: BMC V, p. 600 n. ${ }^{\circ}$ 403. En la parte oriental, concretamente de la ceca de Antioquía, se han atestiguado ejemplos con la siguiente leyenda: Pietas Aug: Anv.: Iulia Maesa Aug.: BMC V, p. 578 n. ${ }^{\circ} 298-299$. 
PEDRO DAVID CONESA NAVARRO

JULIA MAESA Y JULIA SOEMIAS EN LA CORTE DE HELIOGÁBALO:

EL PODER FEMENINO DE LA DOMUS SEVERIAN

junto con alegorías como Laetitia ${ }^{149}$, Concordia ${ }^{150}$, Vesta ${ }^{151}$, Fortuna ${ }^{152}$, Virtus o Venus ${ }^{153}$ conformaron el total de las representaciones relacionadas con la hermana de Julia Domna.

Para el caso de Julia Soemias su nombre en las monedas suele aparecer de dos maneras como viene siendo habitual. O bien con la forma Augusta abreviada o totalmente desarrollada, quedando de la siguiente manera: Iulia Soaemias Aug. o Iulia Soemias Augusta. Sin embargo, posiblemente a causa de una equivocación, se ha atestiguado una variante con la acuñación de Mater Deum S. C., en la que la emperatriz está referida como Iulia Soaemis Augusta ${ }^{154}$.

Las producciones relacionadas con Soemias comenzaron a producirse desde el comienzo del gobierno de Heliogábalo ${ }^{155}$. El número de alegorías fue menor si lo comparamos con las originadas en honor a su madre. De todas ellas destaca por encima del resto la alusión a Venus ${ }^{156}$. Concretamente a Venus Caelestis, que responde a un unicum, pues no se ha atestiguado anteriormente entre sus predecesoras ${ }^{157}$. Mattingly propuso que pudo derivar de un antiguo culto a la divinidad en Emesa, ya que recuerda a la Dea Caelestis de Cartago. En algunas emisiones viene con una estrella en uno de los lados del campo del reverso ${ }^{158}$, producciones estas últimas que se datan a partir del año 220 d. C. en adelante ${ }^{159}$. Se han

149. Laetitia Publ: Anv.: Iulia Maesa Aug.: RIC IV ${ }^{2}$, p. 50 n. ${ }^{\circ}$ 261; BMC V, p. 540 n. ${ }^{\circ} 69$. En Antioquía: Laetitia Publ: Anv.: Iulia Maesa Aug.: BMC V, p. 577 n. ${ }^{\circ}+$.

150. Concordia Augg.: Anv.: Iulia Maesa Aug.: RIC IV ${ }^{2}$, p. 51 n. ${ }^{\circ}$ 277; BMC V, p. 542 n. ${ }^{\circ}$ a. En ambos catálogos se señala que la moneda fue un denario irregular ya que estamos ante un testimonio híbrido, pues el reverso era de Julia Paula.

151. Vesta: $B M C$ V, p. 542 n. ${ }^{\circ}$ c. Moneda híbrida, pues el reverso es de Julia Domna.

152. Fortuna Reduci: Anv: Iulia Maesa Aug.: RIC IV ${ }^{2}$, p. 49 n. 252.

153. Venus Victrix: Anv: Anv.: Iulia Maesa Aug.: RIC IV ${ }^{2}$, p. 50 n. ${ }^{\circ} 275 ; B M C$ V, p. 578 n. ${ }^{\circ *}$

154. RIC IV $\mathrm{IV}^{2}$, p. 60 n. $400 ; B M C$ V, p. 596 n. 374.

155. ROWAN, 2012, p. 216.

156. Rowan, 2011, p. 262 fig. 12; Rowan, 2012, p. 216 fig. 71.

157. ROWAN, 2011, p. 261.

158. Con la estrella en el lado derecho: $B M C$ V, p. 536 n. ${ }^{\circ} 45$; p. 537 n. ${ }^{\circ} 48$. Con la estrella en el lado izquierdo: $B M C$ V, p. 537 n. ${ }^{\circ} 46-47$; p. 537 n. ${ }^{\circ} 49-51$; p. 537 n. ${ }^{\circ} 52-$ 54. En todas las emisiones aparece el nombre de la Augusta desarrollado de la siguiente forma: Iulia Soaemias Aug. También puede aparecer con la leyenda Venus Caelestis S.C.: Anv: Iulia Soaemias Aug.: En el RIC IV ${ }^{2}$, p. 60 n. ${ }^{\circ} 402-405$. En el RIC se indica que la divinidad está estante y girada hacia la izquierda no indicándose el lugar donde se encuentra la estrella. En cuanto al catálogo británico, con esta segunda leyenda en el reverso encontramos la estrella en la izquierda: $B M C$ V, p. 596 n. ${ }^{\circ}$ 375-377. En todas, el nombre de la Augusta aparece desarrollado de la misma forma: Iulia Soaemias Aug.

159. BMC V, p. ccxxxiii. 
atestiguado dos variantes. Por un lado, la diosa estante y sosteniendo una manzana y un cetro ${ }^{160}$ (fig. 3); mientras que, en el otro tipo, Venus está sedente y sostiene los mismos atributos, pero con la particularidad de que hay un Cupido a su lado ${ }^{161}$ (fig. 4). En el Catálogo Británico se atestiguó otra variante a las anteriores en la que aparece la divinidad estante y el dios alado ${ }^{162}$, que, siguiendo la tipología anterior, ambos personajes solo aparecieron juntos cuando Venus se muestra sedente. Dea Caelestis puede que estuviera vinculada con la divinidad púnica Tanit, que encarnó el principio de fertilidad de vida y tierra además de fecundidad. Parece que la introducción del culto en Roma y en los territorios dependientes de la metrópolis data de mediados del siglo II d. C., siendo más numerosos los testimonios ya durante el siglo III d. C. y, concretamente, bajo la dinastía de los Severos cuando se creó un templo a la diosa ${ }^{163}$. Por tanto, el mensaje que se pretendió buscar con la alusión a esta divinidad fue transmitir la idea de Soemias como madre del Augusto ${ }^{164}$.

Tras Venus, Juno es la divinidad más significativa dentro de las acuñaciones relacionadas con Soemias, algo que no se sale de la normalidad. En este caso la diosa siempre aparece estante y de frente. Suele representarse sosteniendo una pátera y un cetro o con palladium o stephane. En cuanto a la leyenda suele ir o bien simplemente con $J u n o^{165}$, que en este caso el nombre de la emperatriz en el reverso viene abreviado, Iulia Soaemias Aug., o Iuno Regina ${ }^{166}$, que entonces se muestra completamente desarrollado, Iulia Soaemias Augusta. El resto de las alegorías fueron empleadas con anterioridad y se repite la misma intencionalidad basada en la transmisión de la maternidad y la alegría que supuso proporcionar al Imperio

160. Anv.: Iulia Soaemias Aug.: BMC V, p. 636 n. ${ }^{\circ}$ 44. Con la leyenda, Venus Caelestis S.C.: Anv.: Iulia Soaemias Aug.: BMC V, p. 597 n. ${ }^{\circ} 385$.

161. BMC V, p. ccxxxiii. Anv: Iulia Soaemias Augu.: BMC V, p. 537 n. ${ }^{\circ}$ 55-56; p. 538 n. ${ }^{\circ}$ 57-60. Rowan, 2011, p. 261. Con la leyenda Venus Caelestis S.C.: Anv: Iulia Soaemias

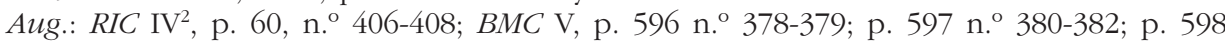
n. ${ }^{\circ} 387$. En el ejemplo número 382 se observa una contramarca detrás de la cabeza de la emperatriz que aparece en el anverso. También hay emisiones de la parte oriental con la alusión a Venus Caelestis. Cf. Venus Caelestis: Anv.: Iulia Soaemias Aug.: BMC V, p. 576 n. ${ }^{\circ} 293$.

162. Anv: Iulia Soaemias Aug.: BMC V, p. 598 n. 386.

163. Uroz Rodríguez, 2004-2005, pp. 169 y 171.

164. Rowan, 2011, p. 261.

165. RIC IV $\mathrm{IV}^{2}$ p. 48 n. ${ }^{\circ} 235$; $B M C$ V, p. 536 n. ${ }^{\circ} 235$

166. RIC IV ${ }^{2}$, p. 48 n. ${ }^{\circ} 236-237$; BMC V, pp. 39-43. 
PEDRO DAVID CONESA NAVARRO

JULIA MAESA Y JULIA SOEMIAS EN LA CORTE DE HELIOGÁBALO:

EL PODER FEMENINO DE LA DOMUS SEVERIAN

a nuevos dignatarios. Las divinidades fueron: Pudicitia ${ }^{167}$, Mater Deum ${ }^{168}$, Saeculi Felicitas ${ }^{169}$, Pietas $^{170}$, Annona ${ }^{171}$ o Vesta. Sobre esta última podemos encontrar dos variantes. En la primera aparece la divinidad sedente sosteniendo un simpulum y un cetro ${ }^{172}$, mientras que cuando está estante lo que lleva en sus manos es un palladium y una lanza ${ }^{173}$.

Al igual que con Julia Maesa, solo hay un testimonio que se haya constatado en el que aparece el emperador junto con la emperatriz. En el anverso aparece la cabeza de Heliogábalo drapeada y girada hacia la derecha, mientras que en el reverso está el busto de su madre. En el anverso no se aprecia la leyenda, que lo normal sería el nombre del emperador, por el contrario, está insertado el nombre de la Augusta: Iulia Soaemias Aug. ${ }^{174}$. No es casual que las virtudes que aparecen representadas en las monedas de Julia Maesa y Soemias estén vinculadas con la maternidad, al igual que ocurre con los títulos honoríficos reflejados en las inscripciones. En su mayoría, tanto las formas desarrolladas como los honores conferidos respondieron a la norma que se estableció desde el principio del Imperio romano. El modo en el que las mujeres se involucraron en los círculos de poder, como es el caso de la domus imperial, fue a través de la exaltación de la maternidad, siendo, por tanto, uno de los mensajes más efectivos, pues su capacidad para engendrar fue decisiva en el contexto político, ya que fueron ellas quienes transfirieron de manera inequívoca el poder imperial ${ }^{175}$.

167. Anv: Iulia Soaemias Aug.: RIC IV ${ }^{2}$, p. 48 n. ${ }^{\circ} 238 ; B M C$ V, 538 n. ${ }^{\circ}$ c. En el catálogo británico se indica que el denario es híbrido ya que el reverso originariamente era de Julia Domna.

168. Mater Deum S.C.: Anv: Iulia Soaemias Augusta: RIC IV ${ }^{2}$, p. 60 n. ${ }^{\circ} 400 ; B M C$ V, p. 595 n. ${ }^{\circ} 373$; p. 596 n. ${ }^{\circ} 374$.

169. Anv: Iulia Soaemias Aug.: RIC IV ${ }^{2}$, p. 48 n. ${ }^{\circ} 239$; BMC V, p. 538 n. ${ }^{\circ}$ d. En el Catálogo Británico se indica que fue híbrido, cuyo reverso es de Julia Maesa.

170. Anv.: Iulia Soemiass Augusta: RIC IV ${ }^{2}$, p. 48 n. ${ }^{\circ} 237 \mathrm{~A} ; B M C$ V, p. 538 n. ${ }^{\circ}$ b. Este último catálogo señala que es un híbrido de Julia Domna.

171. Anv.: Iulia Soaemias Aug.: RIC IV ${ }^{2}$, p. 48 n. ${ }^{\circ}$ 234; BMC V, p. 538 n. ${ }^{\circ}$ a. En el Catálogo Británico se indica que posiblemente fuera de fábrica siria.

172. Anv: Iulia Soaemias Aug.: RIC IV ${ }^{2}$, p. 49 n. ${ }^{\circ} 247 ; B M C$ V, p. 539 n. ${ }^{\circ}$ f. En este último ejemplo a su vez se puede subdividir en dos variantes dependiendo del desarrollo del nombre de la emperatriz en la leyenda del anverso: a) Iulia Soaemias Aug., b) Iulia Soemiass Augusta. Este último ejemplo es híbrido pues el reverso que presenta es de Julia Domna. Con idéntica representación, pero con el nombre y titulatura de la Augusta desarrollado al completo. Cf. RIC IV ${ }^{2}$, p. 49 n. 248.

173. Anv.: Iulia Soaemias Augusta: RIC IV ${ }^{2}$, p. 49 n. ${ }^{\circ} 246 ; B M C$ V, p. 538 n. ${ }^{\circ}$ e.

174. RIC IV ${ }^{2}$, p. 45 n. ${ }^{\circ} 207 ; B M C$ V, p. 535 n. ${ }^{\circ}$ †.

175. Domínguez Arranz, 2017, p. 100. 
Las leyendas desarrolladas en las monedas de ambas mujeres no distaron de las marcadas por sus predecesoras, en especial aquellas que se encontraron relacionadas con la maternidad. Sin embargo, tras lo expuesto sí que hay elementos que nos gustarían analizar detenidamente. Si repasamos las acuñaciones monetales, observamos que con Julia Maesa se utilizaron además de virtudes de Julia Domna, algunas de carácter militar. Esto explicaría el clima de tensión vivido tras la subida al poder de Heliogábalo. Lo extraño es que no se haya constatado hasta la fecha ninguna moneda alusiva a la mater castrorum que, además de ser ampliamente desarrollada por Julia Domna, desde el momento en el que se produjo la concesión de dicho título a Faustina la Menor, se encontró en la titulatura de las emperatrices con un fin político con el que se quiso evidenciar que el ejército y la dinastía estuvieron unidos bajo el amparo de la Augusta. Resultaría difícil de explicar, ya que, por ejemplo, en el registro epigráfico sí que hemos podido comprobar su inclusión en diferentes ejemplos. Que la mayoría de las representaciones desarrolladas por la hermana de Domna estuvieran relacionadas con la exaltación de un tiempo feliz y perpetuo (Saeculi Felicitas, Felicitas Publica, Temporum Felicitas), tendría como fin desarrollar la idea de que con Heliogábalo se inauguró la edad dorada de los Severos. Estas últimas acuñaciones rompieron con las formas típicas desplegadas para las Augustae, donde la maternidad y la fecundidad fueron los temas predilectos. En cuanto a Maesa, además de las típicas virtudes que se repiten en otras mujeres, observarnos cierta "orientalización" en los tipos representados. Sin duda, el tema de Venus Caelestis y Mater Deum fueron los más significativos. A través de las acuñaciones monetales podemos observar que parte de la visión transmitida por las fuentes literarias que nos hablaron de dos comportamientos opuestos parecen confirmarse. En el caso de Maesa se repitieron los cánones establecidos por Julia Domna, además de una especial atención por desarrollar un discurso basado en la felicidad que supuso el nuevo período que se inauguraba. Por el contrario, con Soemias vemos cierta influencia en las culturas desarrolladas en Oriente, posiblemente con formas que nos recordarían a su ciudad natal.

\section{CONClusiones}

En este trabajo hemos pretendido analizar la implicación que tuvieron la abuela y madre de Heliogábalo en su gobierno. Para ello, además de las narraciones de los autores clásicos, hemos repasado su titulatura a partir del tejido epigráfico, así como las principales virtudes que se desarrollaron en sus acuñaciones monetales. Pese a las similitudes que manifestaron, se 
aprecian ciertas diferencias entre ambas Augustae. De hecho, la historiografía científica en general ha tratado de manera desigual a Julia Maesa y a su hija. Mientras que la primera fue caracterizada como una persona con gran inteligencia y astucia, con capacidad para poner en marcha maniobras y estrategias políticas, no ocurrió lo mismo con Julia Soemias, que ha sido menos estudiada ${ }^{176}$. Por otro lado, la pésima publicidad que se hizo de de Heliogábalo también sin duda a su madre y, posiblemente, este hecho fue determinante para que la Historia Augusta la calificara de meretrix, aludiendo a una vida repleta de vicios; por ello mereció el mismo castigo que su hijo. Si bien los autores clásicos afirmaron que en un principio Julia Maesa maniobró para que su nieto mayor fuera proclamado emperador; sin embargo, posteriormente se alejó de él a consecuencia del descontento social generado por sus actos y forma de gobernar. Por el contrario, Julia Soemias siempre se mantuvo fiel a su hijo hasta el final, lo que desencadenó su propia muerte. Tal y como ha dicho Saquete, las actitudes femeninas fueron duramente criticadas en la Historia Augusta, donde se ensalzaron únicamente los aspectos masculinos ${ }^{177}$. Por este motivo, podemos asociar las referencias a la madre del emperador en esta obra a la exageración y el deseo de criticar y censurar el mal gobierno de Heliogábalo.

Es difícil determinar si la retirada a tiempo de Maesa permitió que no sufriera la misma suerte que su hija, más complejo resultaría establecer si esa cuestión condicionó también a la desigualdad la que fueron descritas por las fuentes clásicas. No podemos olvidar que en el mundo romano los lazos familiares estuvieron supeditados al sentimiento de Estado. Por tanto, aunque pueda parecer que Maesa actuó de manera interesada y calculadora al abandonar, en un momento determinando, tanto a su hija mayor como a su nieto, actuó conforme a los mores maiorum. Es decir, bajo la premisa de que la supervivencia dinástica fue lo más importante, no solo consiguió mantener la dinastía de los Severos, sino también la estabilidad de Roma. Esta actitud motivó que, aunque los autores clásicos afirmaron que mantuvo alianzas, incluso a través del soborno, respetaron en gran medida la figura de la poderosa abuela.

También en los testimonios materiales observamos esa misma descompensación entre ambas mujeres. El poder que tuvo Julia aMesa propició que su hija mayor fuera relegada a un segundo plano. Sin embargo, pese a estas diferencias, encontramos a ambas mujeres preocupadas por mantener el gobierno de Heliogábalo. Al margen de la imagen negativa,

176. Entre los diversos ejemplos, cf. Mattingli en el BMC V, p. ccxxxiii: “Unlike her daughter, but like her sister Julia Domna, Maesa had the brains and will- power of a rule".

177. Saquete, 2018, p. 330. 
peyorativa y artificial creada por los autores clásicos y continuada por buena parte de la historiografía, fueron mujeres que, debido a la escasa edad del emperador, tuvieron la ocasión de poder gobernarlo. Sin embargo, parece evidente que no tuvieron un margen de maniobra tan ampliocomo se ha querido ver, pues su condición femenina no se lo permitió. Por tanto, la creación de un Senado puede ser discutida, más si tenemos en cuenta que la única fuente que lo mencionó es la problemática Historia Augusta. Tal y como hemos asegurado, creemos que posiblemente este senaculum femenino realmente fuera una crítica al emperador por dejarse manejar por su madre y, por otro lado, a los patres conscripti por permitir que las Augustae fueran a sus sesiones en algún momento dado. Ahora bien, si no tuvieron ese poder tan destacado, ¿por qué los autores clásicos insistieron en crear dicha imagen? La cuestión es difícil de resolver, cuando no imposible. Los estereotipos de buenos y malos emperadores que se fueron forjando a lo largo de la Historia, también afectaron a las personas de su círculo más próximo. Tampoco podemos obviar que una sociedad como la romana, anclada en las tradiciones patriarcales, no vió con buenos ojos que unas mujeres controlaran las riendas imperiales. Así pues, es posible que esa imagen perversa de Heliogábalo, en parte, se debió a que no solo traspasó los límites religiosos con la introducción de cultos orientales, sino que dejó el gobierno del Imperio en manos femeninas, algo considerado imperdonable.

A priori ciertos testimonios parecen contradecir en gran medida la información de los autores clásicos. De hecho, nos encontramos con mujeres que recibieron los mismos honores que sus predecesoras, y si observamos con detenimiento los otorgados a Julia Soemias, podríamos deducir que se trató de una emperatriz que no gozó de gran importancia, pues únicamente se sabe con seguridad que recibió el título de Augusta. Sin embargo, si se examinan los epígrafes relacionados con su madre, parece que esta última recibió honores que se salieron de los marcados oficialmente. Apelativos como domina, sanctissima o carissima fueron la máxima expresión de algunos particulares que, con el ánimo de conseguir ganarse el favor de la Augusta y del propio emperador, concedieron virtudes a Julia Maesa no atestiguadas con anterioridad. En definitiva, aunque es difícil asegurarlo, es muy probable que estemos ante mujeres poderosas que no solo para sobrevivir, sino también para mantener la dinastía de los Severos tuvieron que lidiar con el ejército y los senadores. Además, pese a que ciertos testimonios materiales parecen inducirnos a pensar que no se salieron de la norma, tampoco podemos obviar las informaciones transmitidas por los diferentes autores clásicos; aunque eso sí, tenemos que tomarlas con suma cautela. 
PEDRO DAVID CONESA NAVARRO

JULIA MAESA Y JULIA SOEMIAS EN LA CORTE DE HELIOGÁBALO: EL PODER FEMENINO DE LA DOMUS SEVERIAN

6. Bibliografía

Ando, C.: Imperial Rome. AD 193 to 284. The Critical Century. Edinburgh, 2012.

De Arrizabalaga y Prado, L.: The Emperor Elagabalus. Fact or Fiction? Cambridge, 2014.

BABELON, J.: Impératrices syriennes. Paris, 1957.

BAHARAL, D.: Victory of propaganda: the dynastic aspect of the imperial propaganda of the Severi: the literary and archaeological evidence $A D$ 193-235. Oxford, 1996.

Baugman, K. E.: "Mamaea's little man: Alexander Severus, his mother and the Germanic War", en Cooper, D. y Phelan, C. (eds.): Motherhood in Antiquity. Cham, 2017, pp. 107-121.

Bellinger, A. R.: The Syrian Tetradrachms of Caracalla and Macrinus. New York, 1940.

Benario, H. W.: "The Titulature of Julia Soaemias and Julia Mamaea: Two Notes", Transactions and Proceedings of the American Philological Association, 90, 1959, pp. 9-14.

Birley, A. R.: "Religion in the Historia Augusta", en Bonamente, G. y Duval, N. (eds.): Historiae Augustae Colloquium Parisinum. Macerata, 1991, pp. 29-58.

Bleckmann, B.: "Die severische Familie und die Soldatenkaiser", en Temporini-Gräfin Vitzthum, H. (ed.): Die Kaiserinnen Roms. Von Livia bis Theodora. München, 2002, pp. 265-339.

Bleckmann, B. y Brandt, H. (eds.): Historia Augusta Colloquium Dusseldorpiense. Bari, 2017.

Bowersock, G. W.: "Herodian and Elagabalus", en Kagan, D. (ed.): Yale Classical Studies. Studies in the Greek Historians, vol. XXIV. LondonNew York-Melbourne, 1975, pp. 229-236.

Bravi, A.: "Romano more. Tradizione e trasgressione di modelli culturali nell'Historia Augusta", en Bonamente, G. y Brandt, H. (eds.): Historiae Augustae colloquim Bambergense. Bari, 2007, pp. 73-82.

Calderini, A.: Le donne dei Severi. Roma, 1945.

CEnerini, F.: Dive e Donne. Mogli, madri, figlie e sorelle degli imperatori romani da Augusto a Comodo. Imola, 2009.

Chastagnol, A.: "Les femmes dans l'ordre sénatorial: titulature et rang social à Rome", Revue Historique, 531, 1, 1979, pp. 3-28.

Cid López, R. M. a : "Las emperatrices sirias y la religión solar. Una nueva valoración", en Alvar, J. C., Blánquez, C. y Wagner, C. G. (eds.): Formas de difusión de las religiones antiguas. Segundo encuentro-coloquio de 
PEDRO DAVID CONESA NAVARRO

JULIA MAESA Y JULIA SOEMIAS EN LA CORTE DE HELIOGÁBALO:

EL PODER FEMENINO DE LA DOMUS SEVERIAN

Arys. Jarandilla de la Vega, diciembre 1990. Madrid,1993, pp. 245268.

Cockell, L. J.: Accessories to Power: Imperial Women's Dress, Adornments, and Attributes in Art and Text. Queensland, 2015.

Conesa NAVARRO, P. D.: "La prefectura del pretorio: auge y "declive" de un cargo militar romano", Antig. crist. 29, 2012-2014, pp. 375-406.

Conesa Navarro, P. D.: "The relationship of Iulia Mamaea and Alexander Severus, a Young imperator. A review through literary sources", en SÁnchez Romero, M. y Cid López, R. M. ${ }^{a}$ (eds.): Motherhood and Infancies in the Mediterranean in Antiquity. Oxford - Philadelphia, 2018, pp. 247-262.

Conesa Navarro, P. D. y GonzÁlez Fernández, R.: «De salvajes a domesticadas: aproximación a un ensayo sobre la justificación de la condición femenina en el mundo romano", Revue des Etudes Anciennes, 117, 1, 2015, pp. 87-108.

Conesa Navarro, P. D. y González Fernández, R.: "Honesta mors. Suicidas y muertes inducidas de mujeres en la Antigua Roma", en RodRíGuEz López, R. y Bravo Bosch, M. ${ }^{\mathrm{a}} \mathrm{J}$. (eds.): Mujeres en tiempos de Augusto. Realidad social e imposición legal. Valencia, 2016, pp. 585-611.

Conesa Navarro, P. D. y González Fernández, R.: "Fuluia Plautilla, instrumento legitimador y político de la dinastía y del prefecto del pretorio", Athenaeum, 104, 1, 2016b, pp. 129-157.

Cordovana, O. D.: "I severi”, en D’Alessio, A., Panella, C. y Rea, R. (eds.): Roma Universalis. L'Impero e la dinastia venuta dall'Africa. Milano, 2018, pp. 36-47.

Domínguez Arranz, A.: “Maternidad y poder femenino en el Alto Imperio: imagen pública de una primera dama", en Cid LóPez, R. M. ${ }^{a}$ (coord.): Madres y maternidades. Construcciones culturales en la civilización clásica. Oviedo, 2009, pp. 215-252.

Domínguez Arranz, A.: "Imágenes del poder en la Roma imperial: política, género y propaganda", Arenal, 24, 1, 2017, pp. 99-131.

Fernández ARDANAZ, S. y GonzÁlez Fernández, R.: "El consensus y la auctoritas en el acceso al poder del emperador Septimio Severo", Antig. crist., 23, 2006, pp. 23-37.

Frézouls, E.: "Le rôle politique des femmes dans l'Histoire Auguste", en Bonamente, G. y Paschoud, F. (eds.): Historia Augustae Colloquium Genevense. Bari, 1994, pp. 121-136.

GaGÉ, J.: "La postérité de Caracalla", Comptes rendus des séances de l'Académie des Inscriptions et Belles-Lettres, 78, 1, 1934, pp. 63-67.

GHEDInI, F.: Giulia Domna tra oriente e occidente. Le fonti archeologiche. Roma, 1984. 
Gilliam, J. F.: "Severan Titles and an Inscription from Puteoli", Classical Philology, 58, 1, 1963, pp. 26-29.

GONZÁlEZ FERnÁNDEZ, R.: "El fasto imperial y los miliarios en el siglo III. La presencia de las Augustae", Lucentum, 36, 2017, pp. 311-324.

González Fernández, R. y Conesa Navarro, P. D.: "Plauciano. La amenaza de la domus Severiana", Potestas, 7, 2014, pp. 27-50.

González Fernández, R. y Conesa Navarro, P. D.: "La dinastía Severa y el nomen Aurellius. Septimio Severo y la gens Aurelia", Athenaeum, 105, 1, 2017, pp. 137-152.

González Fernández, R. y Sancho Gómez, M. P.: "Pautas para el estudio de la relación emperadores-senado (197-251)", Antig. crist., 23, 2006, p. 57-77.

GÜNTHER, E.: «Femaleness Matters: Identity and Identification Processes in the Severan Dynasty", Marburger Beiträge zur Antiken HandelsWirtschafts- und Sozialgeschichte, 34, 2016, pp. 113-168.

HemelrijK, E.: "Fictive Kinship as a Methaphor for Women's Civic Roles", Hermes 138, 4, 2010, pp. 455-469.

Hidalgo de la Vega, M. ${ }^{a}$ J.: Las emperatrices romanas. Sueños de púrpura y poder oculto. Salamanca, 2012.

ICKs, M.: The Crimes of Elababalus. The Life and Legacy of Rome's Decadent Boy Emperor. London-New York, 2013.

Keltanem, M.: "The Public Image of the Four Empreses: Ideal Wives, Mother and Regents?", en SETÄLÄ, P. (ed.): Women, Wealth, and Power in the Roman Empire. Roma, 2002, pp. 105-146.

KemezIs, A.: Greek Narratives of the Roman Empire under the Severans. Cassius Dio, Philostratus and Herodian. Cambridge, 2014.

KemezIs, A.: "The Fall of Elagabalus as Literary Narrative and Political Reality", Historia, 65, 2016, pp. 348-390.

KemezIs, A.: "The Fictions of Tradition in the Later Lives of the Historia Augusta", en Devillers, O. y Sebastiani, B. B. (eds.): Sources et modèles des historiens anciens. Bordeaux. 2018, pp. 307-318.

KetTenhofen, E.: Die syrischen Augustae in der historischen Überlieferung. Ein Beitrag zum Problem der Orientalisierung. Bonn, 1979.

KIENAST, D.: Römische Kaisertabelle. Grundzüge einer römischen Kaiserchronologie. Darmstadt, 2004.

Kosmetatou, E.: "The Public Image of Julia Mamaea. An Epigraphic and Numismatic Inquiry", Latomus, 61, 2, 2002, pp. 398-414.

LENFANT, D.: "De Sardanapale à Élagabal: les avatars d'une figure du povoir", en Molin, M. (ed.): Images et représentations du pouvoir et de l'ordre social dans l'Antiquité. Actes du colloque, Angers, 28-29 mai 1999. Paris, 2001, pp. 45-55. 
EL PODER FEMENINO DE LA DOMUS SEVERIAN

Levick, B.: Julia Domna. Syrian Empress. London-New York, 2007. Lichtenberger, A.: Severus Pius Augustus. Studien zur sakralen Repräsentation und Rezeption der Herrschaft des Septimius Severus und seiner Familie (193-211n. Chr.). Leiden 2011.

Manders, E.: Coining Images of Power. Patterns in the Representation of Roman Emperors on Imperial Coinage, A. D. 193-284. Leiden-Boston, 2012.

MANDER, J.: Portraits of Children on Roman Funerary Monuments. Cambridge, 2013.

Menéndez Argüín, A. R.: “II Parthica: legio apud Roma”, Habis, 34, 2003, pp. 313-321.

Mennen, I.: Power and Status in the Roman Empire AD. 193-284. LeidenBoston, 2011.

Molinier Arbo, A.: "Femmes de pouvoir entre Orient et Occident aux derniers siècles de l'Empire. Réflexions autor du témoignage de l'Histoire Auguste", en Cennerini, F. y Mastrorosa, I. G. (eds.): Donne, istituzioni e società fra tardo antico e alto medioevo. Lecce-Rovato, 2016, pp. 47-80.

Morelli, A. L.: "Il ruolo della mater come simbolo di continuità nella moneta romana", en Angeli Bertinelli, M. G. y Donati, A. (eds.): Misurare il tempo. Misurare lo spazio. Atti del Colloquio AIEGL-Borghesi 2005, Bertinoro, 20-23 ottobre 2005. Faenza, 2006, pp. 57-77.

Morelli, A. L.: "Potere femminile, potere della Mater", en Caltabino, M. C., Raccuia, C. y Santagati, E. (eds.): Tyrannis, Basileia, Imperium. Forme, prassi e simboli del potere politico nel mondo greco e romano. Atti dellle Giornate seminariali in onore di S. Nerina Consolo Langher (Messina 17-19 Dicembre 2007). Messina, 2010a, pp. 459476.

Morelli, A. L.: Madre di uomini e di dèi. La rappresentazione della maternità attraverso la documentazione numismatica di época romana. Bologna, 2010b.

Muñoz Muñoz, F. A. y MarTínez López, C.: "Las virtudes en las monedas imperiales romanas", en MuÑoz MuÑoz, F. A. y Molina RuedA, B. (eds.): Virtudes clásicas para la paz. Granada, 2014, pp. 113-200.

NADOLnY, S.: Die severischen Kaiserframen. Stuttgart, 2016.

Oкоń, D.: Imperatores Severi et Senatores. The History of the Imperial Personnel Policy. Szczecin, 2013.

Oкоń, D.: "Severan Remarks on the Cult and the Titulature of Empresses from the Severan Dynasty", Mnemon, 18, 2, 2018, pp. 142-149.

Di Palma, S.: "Evoluzione dei culti solari a Roma: il Sol Invictus da Settimio ad Alessandro Severo", en Covolo, E. y Ridaldi, G. (eds.): Gli 
Imperatori Severi. Storia Archeologia Religione. Las-Roma, 1999, pp. 333-336.

PAsqualini, A.: "CIL, XIV 2120, la curia mulierum di Lanuvio e l'"associazionismo" delle done romane", en BuONOPANE, A. y CENERINI, F. (eds.): Donna e vita cittadina nella documentazione epigráfica. Atti del II Seminario sulla condizione femminile nella documentazione epigráfica. Verona 25-27 marzo 2004. Faenza, 2005, pp. 259-274.

Penella, R. J.: "Caracalla and His Mother in the "Historia Augusta", Historia: Zeitschrift für Alte Geschichte, 29, 3, 1980, pp. 382-384.

Polley, A. R.: "The Date of Herodian's History", L'Antiquité Classique, 72, 2003, pp. 203-208.

Pomeroy, S. B.: Diosas, rameras, esposas y esclavas. Mujeres en la Antigüedad Clásica. Madrid, 1987.

PotTer, D.: The Roman Empire at Bay AD 180-395. London, 2004.

RAepsaet-Charlier, M.-T.: "A propos de Julia Soaemias, Aelia Gemellina et Vedia Phaedrina", Revue internationale des droits de l'antiquité, 30, 1983, pp. 185-192.

RAEPSAET-CHARLIER, M.-T.: "Matronae equites. La parenté-féminine de l'ordre équestre", en Demougin, S., Devijver, H. y Raepsaet-Charlier, M.-T. (eds.): L'ordre équestre. Histoire d'une aristocratie (II siècle av.J.-C.II siècle ap. J.-C.). Actes du colloque international. (Bruxelles-Leuven, 5-7 octobre 1995). Roma, 1999, pp. 215-236.

Royo Martínez, M. ${ }^{a}$ DEL M.: "Propaganda dinástica, militar y religiosa en las monedas de Julia Domna", Espacio, Tiempo y Forma. Serie II- Historia Antigua, 30, 2017, pp. 299-322.

Rowan, C.: "The Public image of Severan Women", Papers of the British School at Rome, 79, 2011, 241-273.

Rowan, C.: Under divine Auspices. Divine Ideology and the Visualisation of Imperial Power in the Severan Period. Cambridge, 2012.

Ruggini, L. C.: "Elagabalo, Costantino e i culti "siriaci" nella Historia Augusta", en Bonamente, G. y Duval, N. (eds.): Historiae Augustae Colloquium Parisinum. Macerata, 1991, pp. 123-146.

SAAVEDra Guerrero, M. ${ }^{\text {a }}$ D.: "Realidad y ficción. El "poder" de la emperatriz Julia Maesa y la restauración de la dinastía de los Severos", Bulletino dell'Istituto di Diritto Romano "Vittorio Scialoja", 42-43, 2000-2001, pp. 855-865.

SAncho Gómez, M. P.: "La religión del siglo III: Los Severos y la influencia orientalizante de Heliogábalo. Sincretismo, culto imperial, magia y otros ritos mistéricos (199-248)", Antig. crist., 28, 2011a, pp. 595-623.

SANChO Gómez, M. P.: "El prefecto del pretorio: una figura dominante de la política romana en el siglo III (192-284)", Potestas, 4, 2011b, pp. 69-86. 
SAncho Gómez, M. P.: La religión del autor de la "Historia Augusta". Murcia, 2018.

Saquete, J. C.: "La Historia Augusta y las mujeres", en Pavón, P. (ed.): Marginación y mujer en el Imperio romano. Roma, 2018, pp. 315-332.

Scheithauer, A.: "Die Regierungszeit des Kaisers Elagabal in der Darstellung von Cassius Dio und Herodian", Hermes, 118, 3, 1990, pp. 335-356.

Sсотт, A.: "Cassius Dio's Contemporary History as Memoir and its Implications for Authorial Identity", Papers of the Langford Latin Seminar, 17, 2017, pp. 1-23.

Scotт, A.: "Conspiracy as Plot Type in Herodian's Roman History", Mnemosyne, 71, 3, 2018, pp. 434-459.

Sidebottom, H.: "The Date of the Composition of Herodian's History", L'Antiquité Classique, 66, 1997, pp. 271-276.

Straub, J.: "Senaculum, id est mulierum senatus", en STRAub, J. (ed.): Bonner Historia-Augusta-Colloquium 1964/1965. Bonn, 1966, pp. 221-240.

Uroz Rodríguez, H.: "Sobre la temprana aparición de los cultos de Isis, Serapis y Caelestis en Hispania", Lucemtum, 23-24, 2004-2005, pp. 165-180.

VARNER, E. R.: "Portraits, Plots, and Politics: "Damnatio memoriae" and the Images of Imperial Women", Memoirs of the American Academy in Rome, 46, 2001, pp. 41-93.

VARnER, E. R.: Mutilation and Transformation. Damnatio Memoriae and Roman Imperial Portraiture. Leiden-Boston, 2004.

VElaZA, J.: “EEl enigma imposible? Veinte años de estudios sobre la Historia Augusta", en de la Villa, J., Falque Rey, E., González Castro, J. F. y MuÑoz JimÉnez, M. ${ }^{a}$ J. (eds.): Conuentus Classicorum. Temas y formas del Mundo Clásico / Temes i formes del Món Clàssic, vol. 1. Madrid, 2017, pp. 701-730.

Wallinger, E.: Die frauen in der Historia Augusta. Wien, 1990. 
8. IMÁGENES
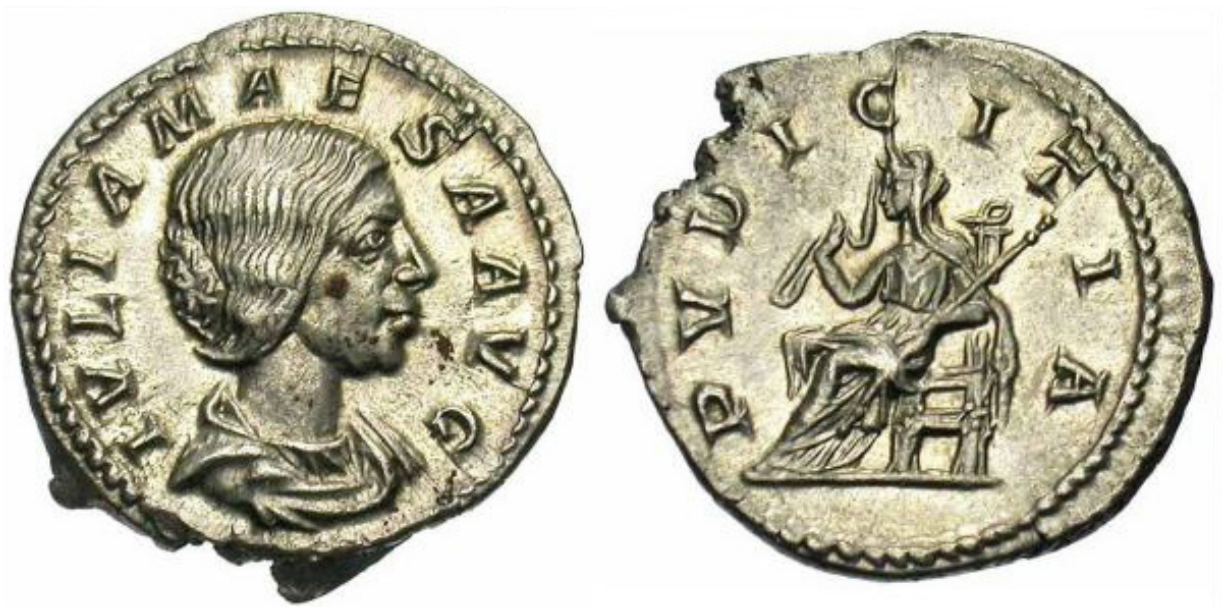

Figura 1. Denario de Julia Maesa con la leyenda en el reverso: Pudicitia. Fuente: http://www.wildwinds.com/coins/ric/julia maesa/RIC 0268.jpg. Consultado: 12/03/2019.
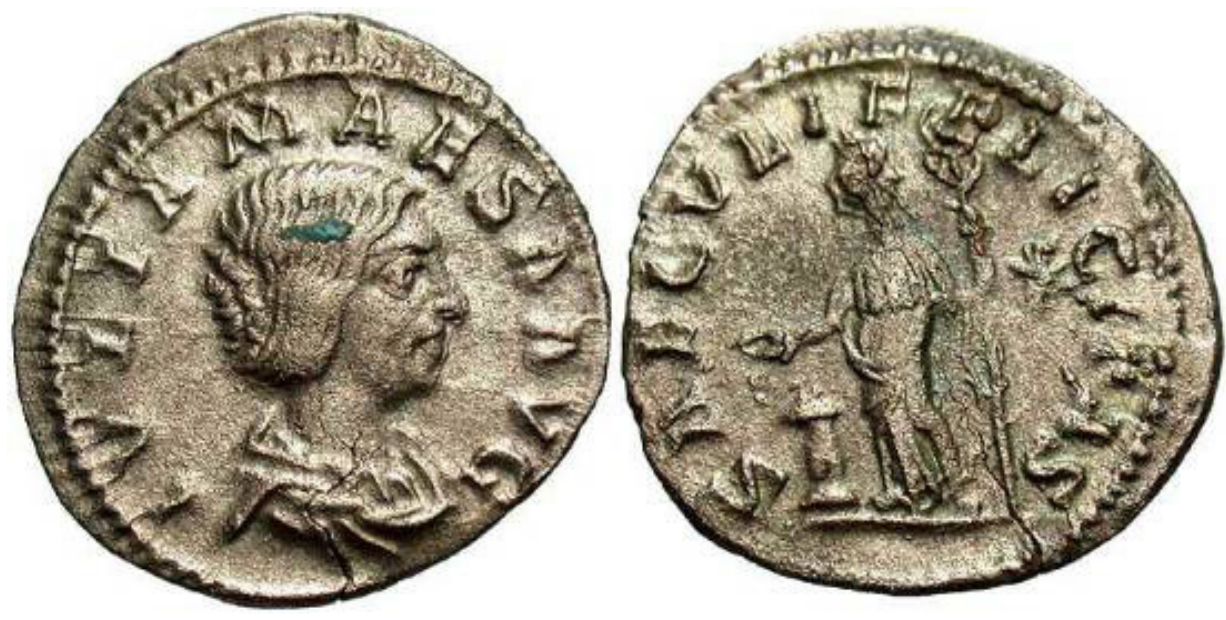

Figura 2. Denario de Julia Maesa con la leyenda en el reverso: Saeculi Felicitas.

Fuente: http://www.wildwinds.com/coins/ric/julia_maesa/RIC 0271.jpg. Consultado: $12 / 03 / 2019$. 
EL PODER FEMENINO DE LA DOMUS SEVERIAN
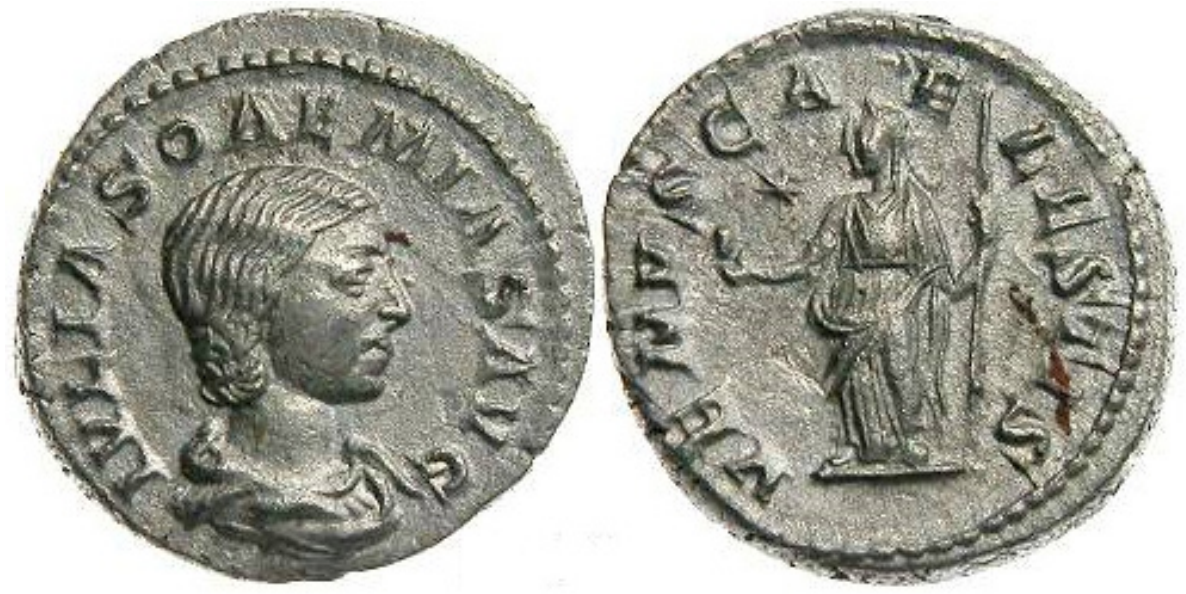

Figura 3. Denario de Julia Soemias con la leyenda en el reverso: Venus Caelestis. La diosa se muestra estante. Fuente: http://www.wildwinds.com/coins/sear5/s7719.html\#RIC 0241.

Consultado: 12/03/2019.
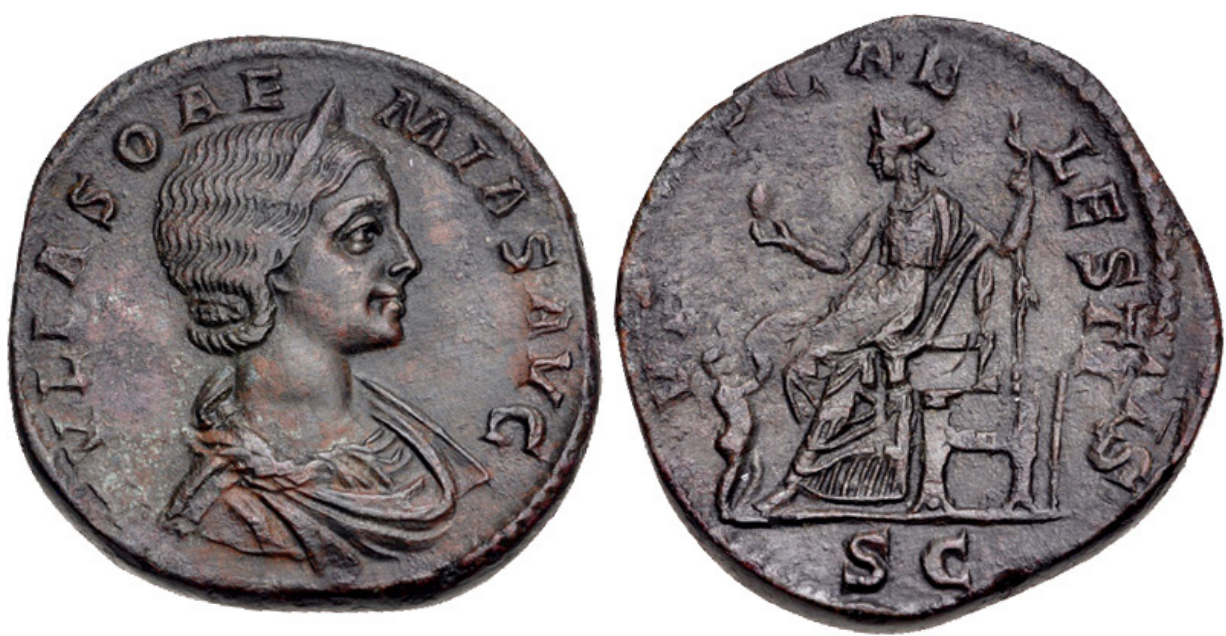

Figura 4. Denario de Julia Soemias con la leyenda en el reverso: Venus Caelestis SC. La diosa se muestra sedente y frente a ella Cupido.

Fuente: https://www.coinarchives.com/302abd9c136b8e89ee555c86fc3c4a6b/img/ cng/e/440/image00462.jpg. Consultado: 12/03/2019. 
